Strictly 4 My N.I.G.G.A.Z: T.H.U.G. L.I.F.E. and My Other Brother (MOB) as Revolutionary Praxis

\author{
A dissertation submitted to the faculty of \\ San Francisco State University \\ In partial fulfillment of \\ The Requirements of \\ The Degree \\ Doctor of Education \\ In \\ Educational Leadership
}

by

Ishman Darnell Anderson

San Francisco, California

May 2020 
Copyright by

Ishman Darnell Anderson

2020 


\section{CERTIFICATION OF APPROVAL}

I certify that I have read Strictly 4 My N.I.G.G.A.Z: T.H.U.G. L.I.F.E and My Other Brother $(M O B)$ as Revolutionary Praxis by Ishman Anderson, and that in my opinion this work meets the criteria for approving a dissertation submitted in partial fulfillment of the requirements for the degree: Doctorate in Educational Leadership at San Francisco State University.

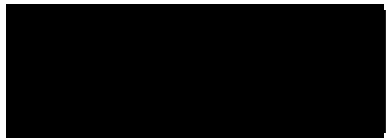

George Bargainer, Ph.D.

Assistant Professor

Criminal Justice Studies

San Francisco State University

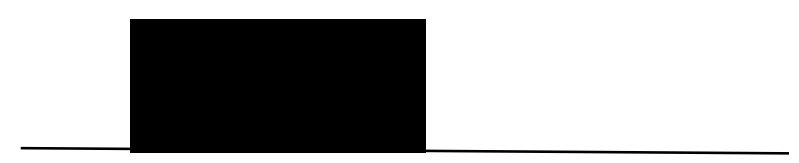

Antwi Akom, Ph.D.

Professor

College of Ethnic Studies

San Francisco State University

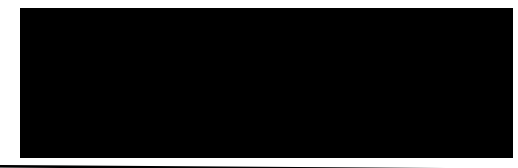

Jeff Duncan-Andrade, Ph.D.

Associate Professor

College of Ethnic Studies

San Francisco State University 


\title{
STRICTLY 4 MY N.I.G.G.A.Z: T.H.U.G. L.I.F.E. AND MY OTHER BROTHER (MOB) AS REVOLUTIONARY PRAXIS
}

\author{
Ishman Anderson \\ San Francisco State University \\ 2020
}

This study examines the impact that My Other Brother (MOB) has on college Black male students in the MOB community organization. In critically examining the narratives of 12 first generation college Black male students in MOB: This study utilizes Tupac Shakur's construct of Thug Life as a theoretical and analytical lens in assessing how Black males in the MOB program navigate processes of alienation. Navigating processes of alienation was placed in context with four critical stages in alignment with Thug Life: These stages emphasized, 1) MOB students' recognition of racism/inequality on an individual level; 2) a recognition of structural level inequality of which they are members of a community of oppressed; 3) a recognition of pride and solidarity in communal struggle; 4) a recognition of political praxis to resist structural racism/dehumanization through education as a function of Black male success. Success was defined based on the following salient concepts expressed by students: 1) Students gaining a heightened sense of confidence and racial pride resulting in students asserting themselves in all educational spaces and life; 2) Students resisting white cultural norms of respectability politics and being affirmed in their "true self" Black identity; 3) Students taking up roles of justice and community leadership in engaging the larger Black community via programming and mentoring K-12 Black youth of the community; 4) Students taking command over their education and their life aspirations. Overall, MOB students feel that they can do whatever they want to do in life: college graduation and access to professional opportunities, entrepreneurship, or community engagement. These outcomes, especially the community and justice component, were grounded in the tenants of Tupac's Thug Life theoretical lens.

I certify that the Abstract is a correct representation of the content of this dissertation.

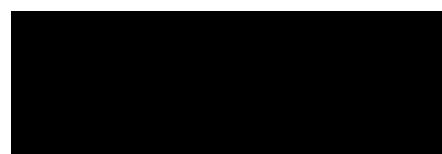

George Barganier, Ph.D. Chair, Dissertation Committee

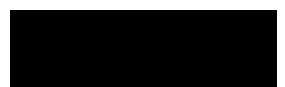

Date 


\section{ACKNOWLEDGMENT}

First, I would like to thank God/Black Jesus and my African and Aboriginal ancestors. I have had many personal conversations with them all throughout these past 3 years. I would also like to thank the students in the MOB organization that participated in this study. Furthermore, I would like to thank a long list of individuals and institutions that shaped who I am today or supported me in my journey. Thank you Mom (Alisa Bourne), Dad (Eugene Anderson), Coach Byrd, Coach Carter, Coach Saucer, Coach Bob Biggs, Coach Moroski, Coach Sanders, Coach Chapla, Robbin Rae, Karlos Carter, Dr. Bruce Haynes, Dr. Miroslava Chavez-Garcia, Ace, Tessa, Dr. Tyrone Howard, Dr. Barbara Henderson, Dr. Jonli Tunstall, Emmanuel Lopez, Auntie Carol, Uncle Greg, Auntie Sue, Jose Salceda, Roshawn Campbell, Diane Petersen, Destiny Walker, Safia Abdul-Sabur, Thomas Byrd, Shawn Fletcher, Daniel Sparks, Dr. Bob Naples, Dr. Christine Wilson, Brett Wilson, Daniel Byrd, Bernie Byrd, William Ramos-Ochoa, Real West Oakland, The Hood', McClymonds Football program, UC Davis Football program, UCLA MSA Cohort and many more. Last, but not least: I want to give thanks and solidarity to my Committee members, Dr. George Bargainer, Dr. Jeff Duncan-Andrade and Dr. Antwi Akom. Finally, I want to say MOB through me, and in peace to my brother Gavin Butler. I know your energy is present Gavin. And MOB in peace to my Granny, Rosa Bourne. 


\section{TABLE OF CONTENTS}

Chapter One: Purpose of the Research..............................................1

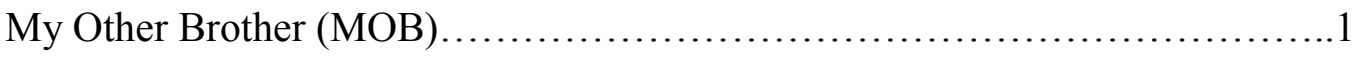

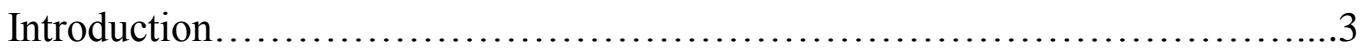

Eurocentrism, Knowledge Production and the Myth of Objectivity...............3

Groundings with My Brothers: A Long Tradition of Radical Resistance.........6

The Significance of Tupac Shakur........................................ 8

Positionality as Founding Director of MOB .................................11

Statement of Problem: Letter Narrative to Tupac Shakur........................12

Purpose of Study ............................................................

Justification............................................................... 31

Chapter Two: Theoretical Framework and Literature...............................34

Theoretical Framework: T.H.U.G. L.I.F.E.............................................................

Thug Life as a Conceptual Framework.....................................36

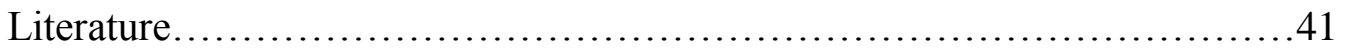

Racism and Black Male Educational Experiences..........................42

Race: Validating Black Males Lived Experiences.........................47

Culture: Validating Black Males Lived Experiences........................48

Gaps in Literature: What Tupac Conveys...............................50

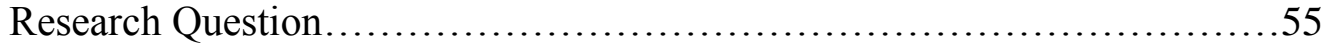

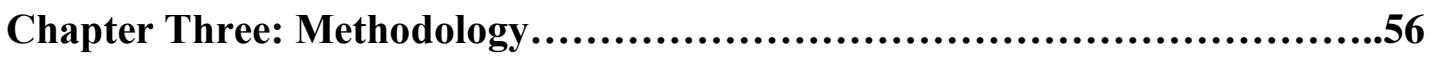

Recruitment Selection..............................................56

Research Design.................................................56 
Context of Study...............................................57

Participant Selection............................................57

Positionality: Relationships with Participants........................57

Access and Protection of Participants..................................58

Data Analysis....................................................59

Chapter Four: Findings..................................................... 62

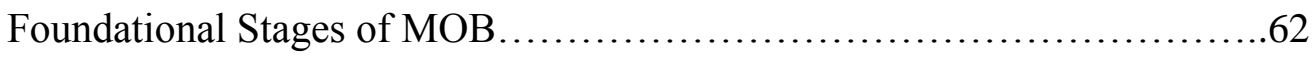

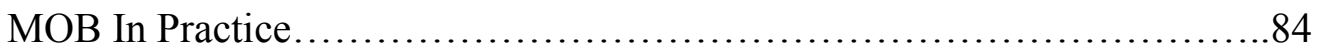

What MOB Means to Black Male Students.............................85

MOB Narratives and Thug Life Concepts..........................87

Most Salient MOB Concepts......................................93

Data Analysis.................................................94

Chapter Five: Discussion, Implications, Conclusion .........................108

Discussion.................................................. 108

Academic Institutional Achievement Through Black Male Resistance......109

Fuck The Academic Institution as Black Male Resistance..................111

Why Being Anti Institution is Critical............................... 112

MOBISM Key Construction.......................................113

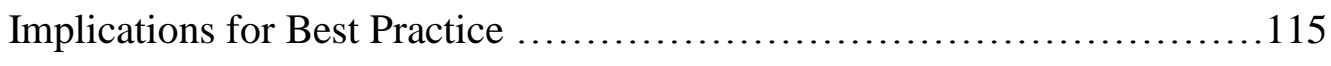

Conclusion: Future Directions..................................117

References......................................................... 119 


\section{Chapter 1: Purpose of Research My Other Brother (MOB)}

The purpose of MOB is to empower Black men and provide them with a counter space and sense of community that will allow students to utilize each other as systems of support to aid in on their success. The core values of MOB are unity, Black culture, culturally validating identity development and K-12 outreach in urban, hood' communities. Rooted in these core values, MOB objective is to develop students into scholars/leaders. Furthermore, to establish a sense of belonging for urban Black youth rooted in mentorship, culture and identity.

At the college level, California State University, East Bay (CSUEB) being the first college partnership via student club on campus; MOB is a cohort of 12 Black men students at CSUEB. It is a community of individuals that support, validate, challenge and grow together. Components are regular intragroup dialogue sessions on Black identity through forms of Hip Hop cultural expression, historical and contemporary racism including internalized racism and contemporary issues in the community at the collegiate level. Furthermore, components include graduate/professional school workshops, financial literacy, leadership development, study sessions and "talk shit" sessions of which students have the space to talk more loosely on contemporary cultural trends that they see in the community that impact them on and off campus. These sessions on campus have been critical in engaging Black men and women and establishing a sense of belonging for them at the college campus, transpiring to their work and engagement with their K-12 youth.

In accomplishing this goal, MOB partners with Castlemont High School in East Oakland, West Oakland Middle School in West Oakland, and McClymonds High School 
in West Oakland in developing a higher education access pipeline of which College MOB student mentors work with K-12 student mentees. At Castlemont High School and McClymonds High School in particular, MOB conducts college readiness programming via weekly A-G requirement meetings, one on one and group academic check ins, after school tutoring and personal check ins with students that focus on student core values and identity development. In addition, MOB K-12 mentor program consists of leadership and research work via weekly Youth Participatory Action Research (YPAR) and community engagement.

As part of this, K-12 MOB youth partake in community-based research projects where students analyze the existing issues and strengths that they see in their surrounding Oakland community to impact practice based on how they construct knowledge. Most critically, MOB mentors develop close connections with K-12 mentees and their families to support students along their experiences in school, and their life experiences outside of school to impact the holistic development of the student. These grassroots, communityoriented approaches to our MOB work sets foundation for my passion to write this dissertation. Furthermore, this dissertation is grounded in the experiences of myself, student participants, and the larger Black community that we are members of. 


\section{Introduction}

This is not your average dissertation. This dissertation is guided and grounded in solidarity with its population of study. It is a dissertation that is not concerned with receiving legitimization from those that may or may not confer it. It is a dissertation that's principal concern is interrupting processes of power that have created Black deficit frameworks that are described, investigated and contested within pages of this dissertation. Most critically, this is a dissertation that privileges the San Francisco State University Educational Leadership Doctoral Program's mission of social justice and equity over the sole purpose of simply obtaining a doctorate degree. The work of MOB is not just "the work." It is my life and commitment to justice via fighting for the humanization of hood 'Black males and working to create and sustain life-thriving realities for the Black community overall. MOB, the sample of 12 students featured in this study, is a small mirror of practice that we hope can inform the larger Black masses and society.

\section{Eurocentrism, Knowledge Production and The Myth of Objectivity}

This work is rooted in the critical Ethnic Studies tradition. As such, it questions the underlying and foundational assumption that knowledge is produced independent of geopolitical contexts. Critical Ethnic studies scholars call for a recognition and critique of Eurocentrism. For these scholars, the historical processes of colonialism affirmed Europe and its forms of knowledge as the center of the world while simultaneously 'subalternizing' the forms of knowledge found in its periphery (Dussel 1995, Grosfoguel 2007, Maldanodo-Torres 2008, Brown and Barganier, 2018). For these scholars, the social sciences are founded on the Eurocentric myth that knowledge can be produced 
objectively. Instead, Ethnic Studies scholars argue for an acknowledgement of the social, political context of the researcher and for a critique from the perspective of the oppressed (Tuhiwai-Smith 1999). This dissertation is guided by these principles. By acknowledging the relationship of the production of knowledge to relations of power, I decenter traditional methods of research and engage the research subjects as active participants in the construction of knowledge. In other words, I have sought to utilize a method and theoretical framing that allows students to participate in meaning making. In this sense, this dissertation is a collaborative effort between myself and other MOB members.

Given that this work follows this tradition, my dissertation differs from traditional works in several key ways: (1). Conceptually: I take a fundamentally different approach to concepts such as "success." Traditionally, success is defined in educational research as educational performance or achievement gap aspirations such as supporting the social and emotional development of Black boys to succeed academically (Harper, 2016). Instead, I understand success by means of students gaining a sense of pride and confidence to resist and interrupt forms of coloniality (which may show up differently from student to student). We view success this way given that this definition of success is rooted in a Black community-cultural framework of resistance that places the historical and contemporary struggle of Black oppression against White colonialism at the forefront of our meaning making systems for success. In connection, we understand that Black male deficit experiences within the school system is just a function of the larger society/system that is anti-Black. As such, on an individual level, a student saying that they felt more encouraged to speak up/assert themselves more in their classes or in life in general based on confidence built through their MOB experiences is an example of 
success when centering MOB outcomes through our historical rebellion lens against racial oppression.

(2). Methodologically: In order to meet these stated ends, we utilized a Black Emancipatory Action Research Approach (BEAR) to allow both myself and students to make meaning of their interviews and data in a Black cultural way experienced by people of African descent (Akom, 2011). (3). In other words, I have attempted to construct a methodology that privileges the knowledge production of my participants. Theoretically: Even further, my work is concerned with highlighting the people's knowledge which is the consciousness of Black students in alignment with the urban Black communities that they come from. To this end, I have sought to construct a theoretical framework that moves beyond those which tend to pathologize many of these groups. Therefore, Tupac Shakur serves as a theoretician that can illuminate the experiences of my subjects with more clarity than traditional education research. (4). Analytically: My data analysis is grounded in the experience of my research participants and how the participants and I constructed meaning making of data together in connection to how we analyzed certain Tupac Shakur lyrics in connection to the data.

(5). Accessibility: This work is intended to serve as a lens that is for the community and by the community. There are existing frameworks in academia that appeal to the consciousness of non-Black educators that are looking for "manuals" and "guides" on how to work with urban Black youth; for example, "For White Folks That Teach in The Hood"-Christopher Emdin, who is a brilliant scholar that you will see in my literature review section of this dissertation. This work, in contrast, is for Blacks of the 
community overall to tap into their very own community cultural power to liberate themselves.

\section{Groundings with My Brothers: A Long Tradition of Radical Resistance}

Revolutionary historian Walter Rodney conveyed the meaning of Black power through his scholarly work "The Groundings with My Brothers.” The Groundings with My brothers is a call for unity amongst the downtrodden members of the Black diaspora (from Black America to the Black Caribbean etc) to build unity amongst each other based on our shared racialized experiences. In connection with The Groundings with My Brothers, Rodney expressed that Black Power is a doctrine about Black people, for Black people, preached by Black people (Rodney, 1969). The concept of "grounding" refers to a collective process and space where Black people could critically engage with each other. In these meetings, Black people determined the confines of the dialogue and came to a political consensus on how to best address their issues. Reflecting on these meetings, Rodney argued, Black people needed,

to 'ground together.' There was all this furor about whites being present in the Black Writers Congress which most whites did not understand. They did not understand that our historical experience has been speaking to white people, whether it be begging white people, justifying ourselves against white people or even vilifying white people. Our whole context has been, 'that is the man to talk to.' Now the new understanding is that Black Brothers must talk to each other. That is a very simple understanding which any reasonable person outside of a particular 'in-group' would understand. That is why we talk about our family discussions. 
Rodney's work here is useful in three central ways: First, Rodney acknowledges the entanglement of knowledge production and politics and grounds his scholarship within his larger political project-Black Power. Secondly, Rodney turns the Eurocentric myth of objectivity on its head by privileging subaltern knowledge. That is to say, Rodney demonstrates that while dominate forms of knowledge tend to disguise social reality, the knowledge created by the masses illuminates the true nature of social relations. For Rodney, "the groundings" were the worldviews of the oppressed and their collective critiques and analyses of relations of power. Lastly, and perhaps even more important, these analyses are rooted in the experiences of the masses. The groundings were a collective process. This is a major departure from traditional academic research that views the people as objects to be studied, rather than actual moral subjects.

These themes are key to the theoretical framing, methodology, and data analysis of this work. This work specifies the importance of making meaning of data, lived experience, and construction of knowledge grounded through a Black power lens given that our Blackness (in a White world) has the biggest impact on our lives. In connecting Groundings with My Brothers to this dissertation, I used Tupac Shakur as an analytical tool given that Tupac best conveys the struggle and Black empowerment in ways that best resonate with the low-income, hood' Black young men featured in this study. Tupac Shakur's construct of Thug Life serves as a contemporary form of people's knowledge, along a radical tradition of Black power. Thus, in tradition of Walter Rodney, Tupac both resonates with the ethos of $\mathrm{MOB}$ and stands as an exceptionally useful lens to analyze how MOB students navigate their experiences with alienation. 


\section{The Significance of Tupac Shakur}

Tupac Shakur had a triple consciousness of love, street survival/thugism, and a revolutionary identity of resistance grounded in the duality of his pre-birth and post birth experiences along the struggles of the oppressed Black masses. To unpack this a little more, we should start with examining his pre-birth experience of being in the belly of his pregnant Black Panther Party mother, Afeni Shakur, while she was in a New York Prison fighting a conspiracy case against the United States government. Tupac being born one month after Afeni Shakur was acquitted of those charges in 1971, was born into an indigenous, revolutionary world culture of resistance grounded in the practices of the Black Panther Party (Shakur, 2019). Like Afeni, Tupac's Godfather Jeronimo Pratt and Stepfather Mutulu Shakur were very important figures in the Black Liberation Movement. Moreover, Tupac was named after "Tupac Amaru II," an $18^{\text {th }}$ century Inca Peruvian revolutionary who lead an Indigenous uprising against European/Spanish rule. When connecting the circumstances surrounding Tupac's name and being born into a Black Panther Party family, one could see the shaping of Tupac Shakur as a freedom fighter for justice.

Revolutionary practices of the Black Panther Party fueled the consciousness of the Black masses in predominate inner-city communities of the 1960s and 70s (Shakur, 2019). As Tupac was born in, and in alignment with the inner-city Black masses, his post-birth experiences continued to reflect the radical resistance teachings of his Black Panther/Liberation Army family. This was also intertwined with the collective struggles of the inner-city Black community of the 1970s-90s of which Tupac grew up in. In connection, the urban Black community was not just a place of radical resistance, but it 
was also a place of high poverty rates, drug dealing, drug abuse, prostitution, gangs and violence due to systematic racism. Through Tupac's experience growing up in East Harlem/New York, Baltimore, and his relocation to Marin City Jungles/Oakland and then LA; his influences were Black revolutionaries, street thugs, gangsters, pimps, drug dealers, prostitutes, dope fiends and hustlers collectively as these people were part of his day to day reality as a Black man in the urban ghettos that he grew up in. Also, his mother Afeni who at one point was on drugs (crack cocaine) during aspects of Tupac's upbringing, remained a symbol of strength and love for Tupac that he would also embrace within his consciousness and music.

As you can see, much of the framing that I am discussing here are experiences of Tupac prior to him being the artist that we would come to know today as a legend. These experiences of love, thugism/street life, and political revolution are grounded in Tupac. Most important, these experiences help us understand the duality of Tupac's lifestyle and work that impacts generations of Black youth that also witness a duality of experiences in their inner-city Black struggle. Tupac has many rap songs that focus on revolution solely, love solely, and street life/thugism solely. He also has music that blends all these themes together. The below Tupac lyrics are an example of the duality within Tupac's work.

"Born thuggin and lovin the way I came up

Big money clutchin', bustin" while evadin' cocaine busts

My pulse rushin, send my pulse into insanity

they shot at my cousin now we bustin' at they whole' family

The coppers want to see me buried, I ain't worried

I got a line on the D.A. 'cause I'm fuckin his secretary 
I black out and start cussin, bust 'em and touch 'em all

They panic and bitches duckin, I rush 'em and fuck 'em all

I'll probably be an old man before I understand

Why I had to live my life with pistols close at hand

they kidnapped my homey's sister, cut her face up bad

They even raped her, so we blazed they pad

Automatic shots rang out, on every block

They puttin hits out on politicians, even cops" (Shakur, 2001).

In these lyrics, you can see Tupac's expression of love and concern for the cousin and sister that was brutalized, a sense of street life/violence via "bustin while evading cocaine busts," and revolution in the form of "putting hits out on politicians, even cops." This duality found in his lyrics is the reason Tupac is so relatable to the Black masses as these experiences represent a duality found in the oppressed Black Mass communities. In this case, Tupac is not important despite of his contradictions and duality. Rather, Tupac is important because of his contradictions and duality.

Tupac was the center of much controversy throughout his legacy and his messages of Black unity, solidarity, love, street life/thugism and revolution were prevalent through the many brush ins with the law that he encountered. Furthermore, the context surrounding Tupac's death. Tupac's many issues were connected to his fight for liberation. Understanding the meaning of Blackness in a White world, is to understand oppressive forces targeting anything that is Black and powerful. To speak to this: The White controlled media in the U.S. painted Tupac's image in a light that is different than that of the people. Centering Tupac's legacy and impact through the people's knowledge, 
is to pay closer attention to how the Black masses in the community are impacted by

Tupac Shakur opposed to how the media portrays him. WTupac Shakur continues to have an impact on a young generation of Black youth along their racialized experiences as a source of empowerment.

\section{Positionality as Founding Director of MOB}

To have a deep and correct understanding of what Thug Life means, it is important to understand how Tupac Shakur (the person that diagnosed the Thug Life Framework) made meaning of his very own concept which is connected to Tupac's life experiences. This collective understanding is important to building empathy amongst the larger community that strives to be empowered by the said frameworks which insures successful implementation of the practice. If a generation misunderstands and misappropriates a culture of practice, the next generation can always get it right by going back to the direct source to examine what the original goals and intentions of the culture of practice was set for.

For example, there are some inner-city Black youth that steal from, and kill other Blacks for the purpose of personal and street disputes between each other. Some of these individuals think they are real thugs and claim to "live a thug life." Yet, this is an example of when a generation has the idea and cultural practice of Thug Life all wrong. In understanding the true meaning of Thug Life via the framework and practice that was documented by Tupac Shakur: One would understand that Thug Life would be the process of those inner-city Black youth organizing systematically to spark revolution against colonial powers, instead of harming one another. 
In connection to MOB, I want to be sure to lay a narrative for the audience to understand my lived experiences that set foundation for my construction and creation of the My Other Brother (MOB) program. This is for the goal of future generations to come, to at least understand what I was/am trying to accomplish with this work. This study is the first attempt to see if MOB study participants make meaning of their experiences in the program in the way that the author had hoped to impact. Through a letter that I wrote to Tupac Shakur to center the Statement of Problem, I take you on a narrative of experiences of oppression that I have encountered and witnessed within my community and higher education experiences that sparked the creation of the MOB program. Most important, this experience reflects how I was able to overcome through a narrative of Thug Life that set the foundation for my MOB work.

\section{Statement of Problem: Letter Narrative to Tupac Shakur}

Black males in America are being systematically oppressed with respect to health, education, employment, income, and overall well-being. The most reliable data consistently indicate that Black males constitute a segment of the population that is distinguished by hardships, disadvantages, and vulnerability (Noguera, 2008). This especially connects to how Black males are treated in schools. Black people represent five percent of California's K-12 student population, yet account for $18 \%$ of all the state's K-12 suspensions (Harris III \& Wood, 2013). Moreover, Black males still have the highest suspension rate, are at the bottom of academic achievement, and are disproportionately to this day, still pushed out of school at alarming rates (Duncan, 2002; Duncan-Andrade \& Morrell, 2008; Noguera, 2003, 2012). To be clear, the problem is anti-Black racism and structural racialization and how it impacts young Black males in 
and outside of educational experiences. MOB aims to reverse this trend by improving educational and cultural content knowledge while fostering Black male student agency to resist oppression. In alignment with community strengths, Tupac's life work highlights resistance, agency, and political contestation against structural racialization.

Dear Tupac Amaru Shakur,

I have always been inspired by your bravery that you have displayed in your life. It has been your legacy, spirit, and strength that keep me pushing forward throughout my struggles and accomplishments as a hood Black man in this "White man's World." In this world, I have shifting moments of happiness in my life, similar to a roller coaster ride riddled with highs and lows. I am happy when I am building with my Brothas in the MOB, engaging students in my role as a College Instructor, and interacting with peers at work, school or in the hood in West Oakland. These experiences are typically when I smile. Outside of these experiences, I carry a burden of stress, yet pride and good energy along this game of life that I am living. I try my best to keep good energy, although I must admit that sometimes my economic and racialized experiences keep a stern look on my face even though I yearn to smile. Below are some of my personal experiences growing up in my community that provides a foundation for the strengths that are part of my community that have helped me be successful. These experiences provided me with validation of who I am as a Black man and a source of capital that helped me navigate through the k-12 system that was set up for me to fail in the first place. I want to thank you Pac because Thug Life came to be something that I understand and resonated with as a youth. I never knew who Paulo Freire and "Pedagogy of the oppressed" was. But I, the Black masses overall from the hood, knew who Tupac and Thug life was/is. 
In terms of my background in connection to Thug Life, I grew up in the Real West Oakland (not the gentrified West Oakland) with a culture of being tough, real, and unified with a sense of community. Sometimes we took that toughness out on each other (which is not a good thing), but the overarching, unconscious understanding was that being a Black man meant that you had to be family oriented and tough-at least within the inner-city hood Black struggle. During this time, the message was that you are a Black man in this world and the system is against you. "You don't need to be fighting one another, you are brothers"----this was the first unifying message that I understood for what being a Black man represented in 1999 when I got into a fight with one of my best friends in elementary school. This was after myself and my patna (the other man behind me in the elementary school picture below) got into a fist fight in the streets. When we came home and Uncle Greg, my patnas father, found out; he explained that we should not be fighting with one another because we are family and should have each other's back. Uncle Greg said that "yall are brothers." I now understand that these implications of Blackness in my childhood were embedded in your Thug Life framework from the streets Tupac. I did not understand the Black Panther party connection to thug Life just yet during this time. However, the foundation of "family," "toughness," and "community" via Thug Life was understood by me as a young West Oakland kid in the hood. I remember the police kicking Uncle Greg's door in, in West Oakland. Myself, my best friend that I got into a fight with and the rest of the family were in the house when this happened. The police shot and killed our dog and vandalized the entire house and pointed guns at all of us. They were looking for Uncle Greg and looking for drugs in the house. Uncle Greg was not there during this time though. We were all about 9 and 10 
years old when we saw this. I knew from this experience and many other encounters with the police, including witnessing my mom deal with the police and the police putting my mom in hand cuffs (taking her from our home and to jail right before my own eyes), that the police were not in my community to help us. I felt that they were the "bad guys" against us. In contrast, I always felt affirmed when I was running around in the streets of West Oakland with my friends, my "family" from the hood/community. I unconsciously grew to look to my own community as a sense of "protecting and serving ourselves," as the police appeared to be in my hood community to bring pain and terror against us. This is critical Pac because your Thug Life framework was also birthed out of the inner-city hood Black struggle, with police brutality and rebellion against this type of oppression being a critical focus of Thug Life.

As a result of Black oppression from racist law enforcement as well as Black on Black crime, being tough/strong and also having a sense of family with your people in the hood and standing up for yourself is what street Black culture represented during this time to me. This street Black culture, I would grow up to recognize this as Thug Life. While this type of community education and knowledge was in alignment with our racialized lived experiences as Black males of the hood (extending outside of the classroom), this Thug Life identity was threatening to White colonial systems. In school, many students that got suspended and kicked out of schools were of this perceived mentality/identity. Students were perceived as "thuggish," "aggressive or disruptive" in the classroom as many teachers perceived us based on how we chose to express ourselves and our values/behaviors within the class. Pac I know that you talked about these types of issues in "Words of Wisdom." 
"In one way or another America will find a way to eliminate the problem, one by one. The problem is the troublesome Black youth of the ghettos

And, one by one, we are being wiped off the face of this Earth

At an extremely alarming rate" (Shakur, 1991).

Our expressions as young Black males in school were connected to our racialized experiences outside of school in our communities and larger society dealing with racial oppressions. Especially racist encounters with White police in our community, poverty, family drug abuse and drug selling for survival, prostitution and sexual violence against Black women, and Black on Black turf/neighborhood and personal violence against one another. This was aspects of our reality outside of school. These were the deficits of Black males and the community overall. As a result, a sense of community, love, resiliency, resistance, affirmation, and family was the strength-based counter to the negative struggles that we faced. These positive experiences of community, love, and family were also prevalent in the midst of the pain and toxicity within our community. Still though, we were stuck with the reality of being in schools that could only address the problems that they saw in us Black males, but not the root cause for these larger issues that we faced. Pac, you discussed this dual reality of anti-Blackness in the community via the police and other internal inner-city Black struggles. Yet, in your lyrics, you always followed up with some source of empowerment in spite of your circumstances, -rooted in education and affirmation of our struggles and racialized experiences to serve our community.

"These are lies that we all accepted

Say no to drugs but the governments' kept it

The Police Running through our community, killing the unity, The war on drugs is a war on you and me And yet, they say this is the Home of The Free 
But if you ask me, it's all about hypocrisy The constitution, yo, it don't apply to me And Lady Liberty? Stupid bitch lied to me This made me strong, and no one's gonna like what I'm pumpin'

But its wrong to keep someone from learning something So get up, its time to start nation building I'm fed up, we gotta start teaching children That they can be all that they wanna be There's much more to life than just poverty" (Shakur, 1991).

Photo 1: Spring 1998, (9 year old Ish, with close Patnas that I grew up with in West Oakland): Hoover Elementary School graduation, Ghost Town Neighborhood in West Oakland. Uncle Greg wrapping his arms around myself and my brothers/friends

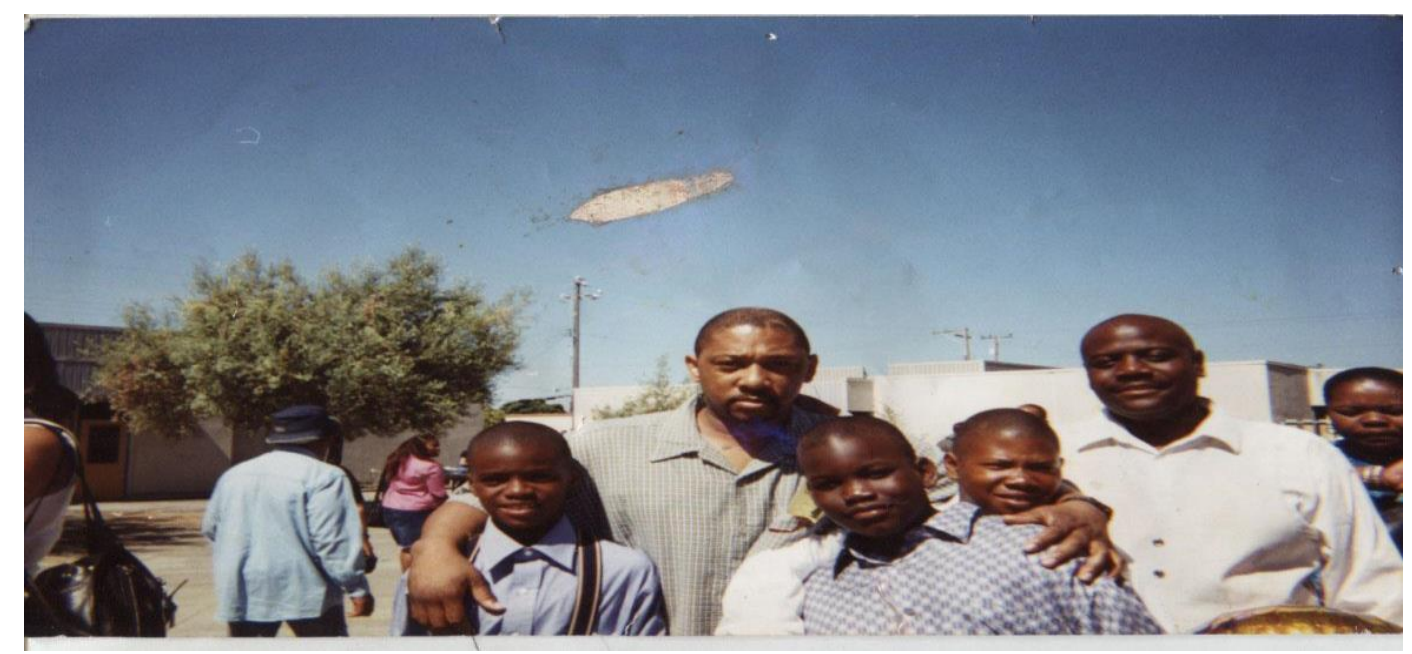

The transition to middle school and then high school is when I began to see stages of anti-urban Black male identity take fold within educational spaces via policies and selective practices from teachers. What I witnessed and experienced growing up serves as a qualitative narrative behind the much existing quantitative data that highlight Black male deficits via not being engaged in K-12 and being criminalized, pushed out due to urban Black male identity. From a quantitative standpoint, only 41 percent of Black males graduate from high school. Black males are 3.6 times more likely to be suspended 
from school than the state average; subsequently, connecting to school to prison pipeline and prison industrial complex (Fryer, Heaton, Levitt, \& Murphy, 2006). Black males are still the highest incarcerated group in America despite Black Americans comprising less than $13 \%$ of all citizens (Fryer, Heaton, Levitt, \& Murphy, 2006). And in in higher education, Black males continue to have low retention and graduation rates on a national level (Harper, 2013).

In qualifying the above quantitative data: As I transitioned to middle School and then high School as a student athlete at McClymonds High School, my friends that are in the above Hoover elementary picture with me had begun the beginning stages of the school to prison pipeline and started being written off as thugs, kicked out of schools and getting more into street politics. I, on the other hand, -who was deemed "thuggish" right along with them up until I became a football player, started receiving different treatment from teachers and began to be socialized as a "good student with potential." I essentially started to be socially tracked and separated from my friends who I had rolled with in elementary and middle school as I became a standout McClymonds football player and pushed into more leadership and college-access programs at McClymonds.

The larger problem in connection to this narrative is: What about the rest of the Black males that were not athletes in west Oakland or inner city Black America in general? Why were they not affirmed, judged and essentially pushed out of the K-12 system?

"June 16th, 1971

Mama gave birth to a hell-raisin' heavenly son

See, the doctor tried to smack me, but I smacked him back 
My first words was, "Thug for life!" and "Papa, pass the MAC!" (Shakur, 1994)

Having a mentality that would say "the doctor tried to smack me, but I smacked him back" as Tupac mentioned (rebellion/resistance) played out differently for me as an athlete in comparison to my friends that did not get socialized into athletics in high school. My peers were pushed out of K-12 because of this "thug" mentality of rebellion/resistance. Meanwhile, as an athlete I was able to be engaged in a way that allowed me to bring my community and racialized experiences to the team and be developed and channeled in a way that allowed me to grow. Sports, and many aspects like the military, are always spaces that "allow" the type of Black male expression of resistance that we hood Black males possess. However, what was out there for Black males, for my patnas in the picture that I grew up with that are not athletes? What could engage them in a way that provides them with a sense of brotherhood and structure allowing them to still be the tough/rebellious men that they are? How do we nurture this in a successful way as strength given that young Black males find these strengths and validation in the streets/gangs and the larger community outside of the school when the school does not engage them?

Photo 2: 16 year old Ish in the Hallways of McClymonds high school, part of the killa 20's hood in West Oakland. 

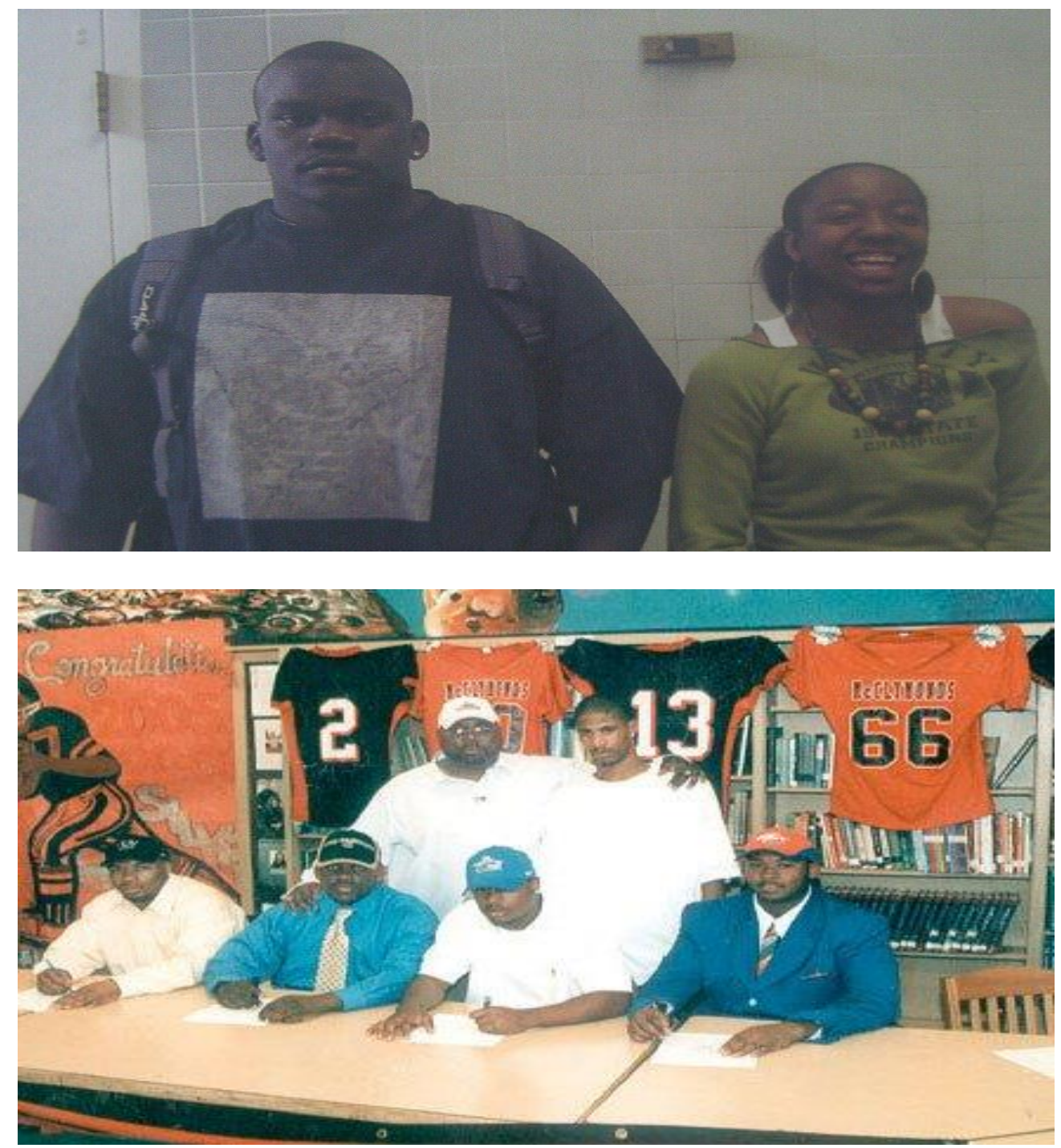

Photo 3: National signing Day, 2007: Myself and 4 of my peers sign our letter of intents to the Universities that we would attend, that we received full ride football scholarships to. UC Davis, Boise State University, San Jose State University, South East Missouri State, University of Washington. One of my friends in the picture wound up catching a case and doing 7 years in federal prison before he could make it to South East Missouri State. Aside from us few students that received athletic scholarships and the students that went to college in general for academics, where did the rest of the Black males at McClymonds end up? And Why? 


\section{Letter to Tupac: Narrative continued:}

In connecting back to you Pac, I studied your life and how you lived a life of pain and happiness based on your hood' Black male identity. Your Black power, your strength and resiliency proved to be capital. You utilized your racialized experiences in an art form that turned you into the rose that grew from the concrete in becoming a millionaire and the most influential person that my generation has ever seen. Furthermore, you lived out Thug Life and put the teachings of your Black Panther parents to practice, by shooting two "crooked" and racist White police officers that were beating up an unarmed Black man on the streets in order to protect that Black person. Yet, these same racialized experiences that you encountered were the source of your persecution. You were unlawfully beaten up by racist White cops in Oakland. Furthermore, the target for FBI counter intelligence just as the Black Panther Party was due to your revolutionary background and rebellion against the system (Newton, 1980). You were shot 5 times in an elevator by Black men, members of your very own Black race, and had falsified rape allegations against you by a Black woman. This was an attempt to slander and assassinate your name and character before the eyes of the world.

Through all of these struggles, you showed strength and resiliency in continuing to speak truth to power and continuing to show love and education to our community with your rap music, poetry, and community engagement. Your artistry was and is educational to the Black mases Tupac. This is critical because your scholarship is different from those of the formal academy. I could not write a letter to someone in the academy that informs my research because I only know his or her research. However, Pac, it is your life style and how you lived out the very work that you produced in your 
artistry that affects me and informs my work. Through your own actions, you taught me that my resiliency, authenticity and racial pride/education of self is a source of empowerment. It is a source of my bravery, persistence, and belief in my own self and my aspirations.

"Words of Wisdom

Based upon the strength of a nation

Conquer the enemy armed with education

Protect yourself, reach for what you want to do

Know thyself, teach about what we've been through

Armed with the knowledge of the place we've been

No one will ever oppress this race again" (Shakur, 1991).

I navigated a predominately White and Asian UC Davis campus with gold teeth in my mouth, a fitted hat and a Black beanie in being outspoken and proactive in seeking out professors, administrators and anyone necessary to reach my goals. The sacrifice was worth it as I do not owe a dime to UC Davis due to being on full ride football scholarship my entire 4 years. Yet, I was still very poor and struggled at UC Davis and many people questioned if I would be able to persist at UC Davis. In addition to UC Davis being a foreign environment to me, as a student athlete I had to sleep on various friends couches and lived a life of highs and lows as I would go back and forth from UC Davis to Oakland to deal with family/community issues while still navigating UC Davis throughout my 4 years there.

Still during these experiences, I excelled on campus both as an athlete and within Black cultural programs such as Africans/African Americans Cultivating Education 
(ACE) and Black Student Union (BSU). The BSU and ACE was critical in giving me that space on campus to build community with other Black students and take part in various cultural programs that educated us in our history and culture. This, along with the relationships that I built within the UC Davis Football program, definitely gave me a sense of belonging at UC Davis and contributed to my persistence. In addition, leadership experiences such as my time as a Student Outreach Assistant with Early Academic Outreach Program (EAOP) contributed to my engagement on campus.

These experiences not only kept me grounded with a sense of family and community on campus, essentially a home away from my home from West Oakland. It connected me to the necessary staff and faculty on campus that affirmed me and pushed me to be the best that I could as an upcoming professional. In connection to the community and racialized culture that serves as street capital from West Oakland, which is a function of Thug Life: When I found these elements at the college institution via programs like EAOP, BSU and ACE, I wound up persisting to graduate from UC Davis in 4 years. While I would say that my leadership experiences and the relationships that I made across all cultures and racial lines at UC Davis impacted my success, it was my Black community and cultural expression from West Oakland that served as a foundation for my confidence in building those necessary relationships to seek out various experiences on campus.

Photo 4: After beating Sacramento State University in our Causeway Classic, 2010 or 2011. Amongst diverse peers on the football team, I was known for representing West Oakland and receiving respect for my authenticity amongst my teammates throughout my career. In the middle kneeling, blue head band wrapped around my shaved head, 
representing West Oakland with my hand gesture. This street cultural and Black pride helped me out a lot while I was at UC Davis. Throughout all of my struggles, these strengths helped me survive.

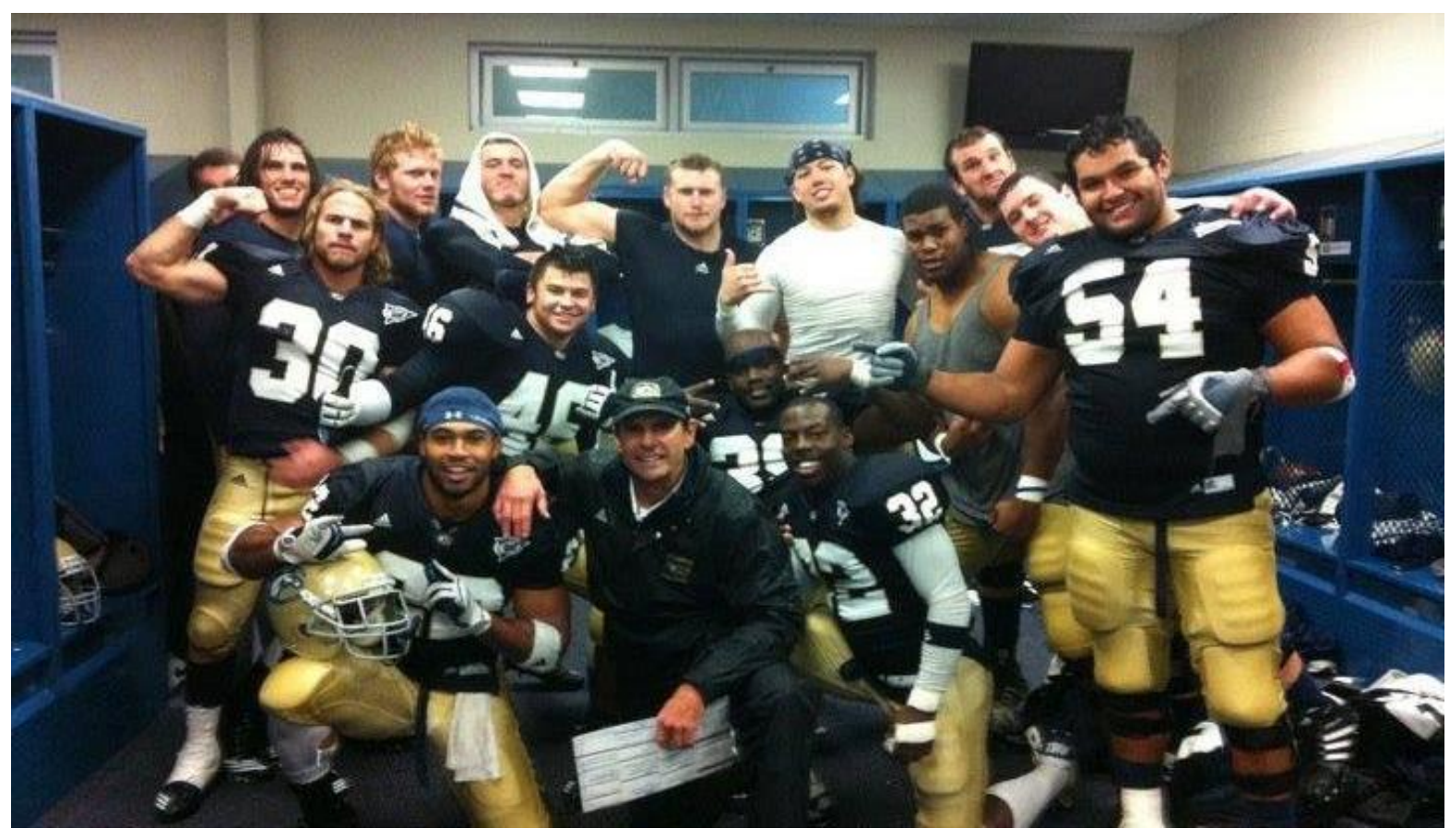

Photo 5: Graduated from UC Davis in 2011. 


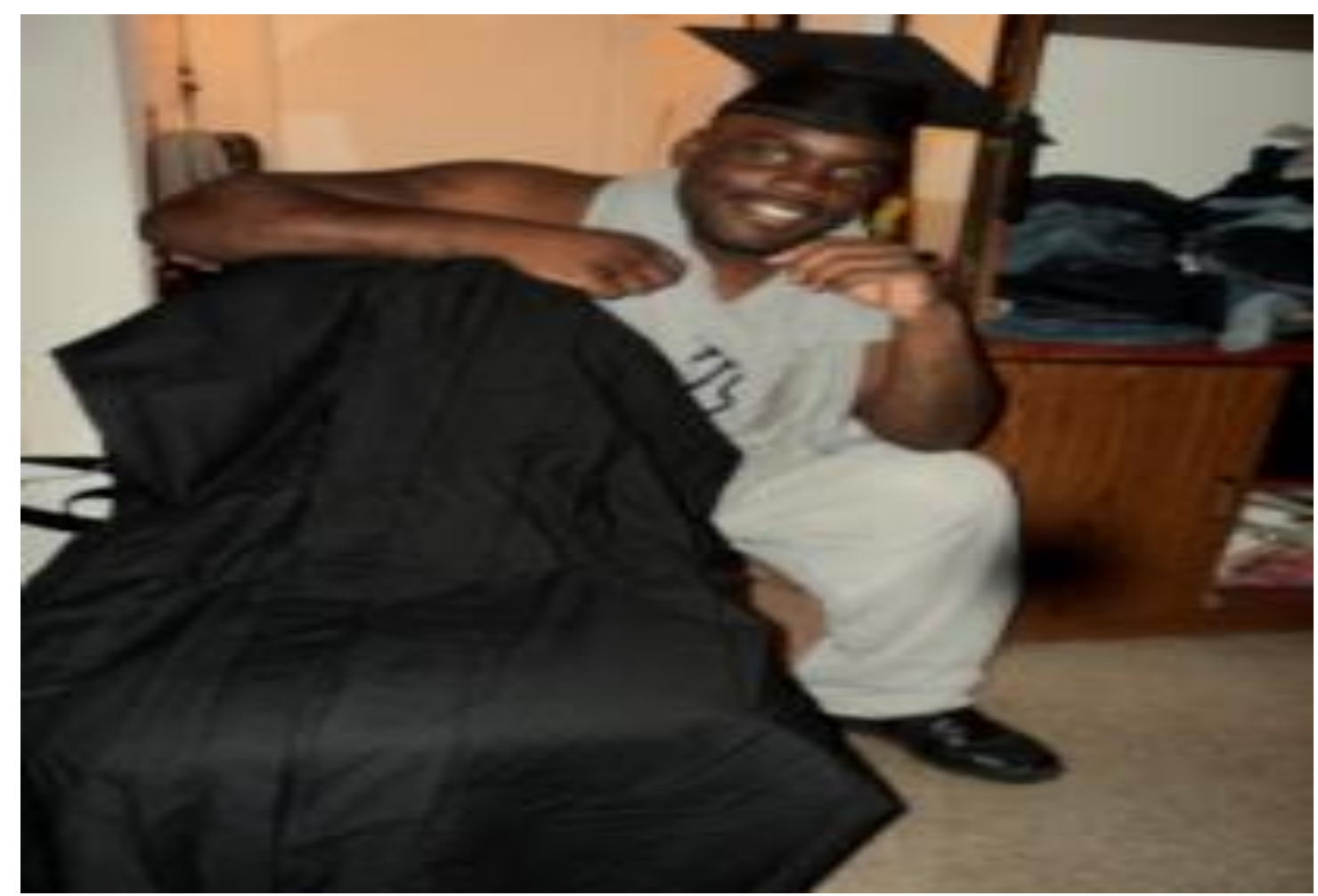

\section{Letter to Tupac: Continued}

Pac, it is interesting because after graduating UC Davis I went on to earn a Master's degree from UCLA in 2013 and dove right into a career in Higher Education, Student Affairs. My goal was to impact my community just like you. Similar to your culture and identity being a strength and yet the subject for your persecution, I began a similar experience once I got into the professional world as a working professional. In my professional experiences as an EOP Counselor (Black woman Director), Academic Advisor at SFSU (White woman Director), Scholar Match College Advisor (White woman director), and Program Coordinator for MESA (Black male director), I have been judged based on my Black hood' cultural dress attire, Black male image, Black language/voice and overall energy. Pac, you were judged by these things from racist White law enforcement and judicial system, record company executives, misguided Black street gangsters, the media and the bourgeois Blacks in the world who could not 
resonate with your racialized and community cultural experiences. This set foundation for your rebellious identity and the code of Thug Life. And in this same token, your cultural expression was celebrated and praised amongst the people that matter; which is the masses and the real community and youth that could identify. And in spite of my judgments and negative experiences from the power structure in the education system, I have always been celebrated and praised for my work by the people that matter; the underrepresented students and students from marginalized communities that I serve.

As I am coming to the end of this letter Tupac, I have one last protest and something that I wanted to run by you. I want to articulate that the leadership amongst the higher education administrators in my experience have all been like robots, pushing a seemingly trained and rehearsed message of the importance of "code switching," "playing the game," "get to the dinner table," and "dress professional." Of which all of their advice has been to tone down my Blackness in some context. This is a form of respectability politics, whether these individuals want to admit it or not. The individuals that are in power (the directors and Vice chancellors etc) are considered to be "educational leaders" and I am considered to be a talented individual that does great work but needs to be "refined." This is the false construct and the larger problem of practice here. This is why I created my own leadership and power for myself and Black males alike with the MOB. 

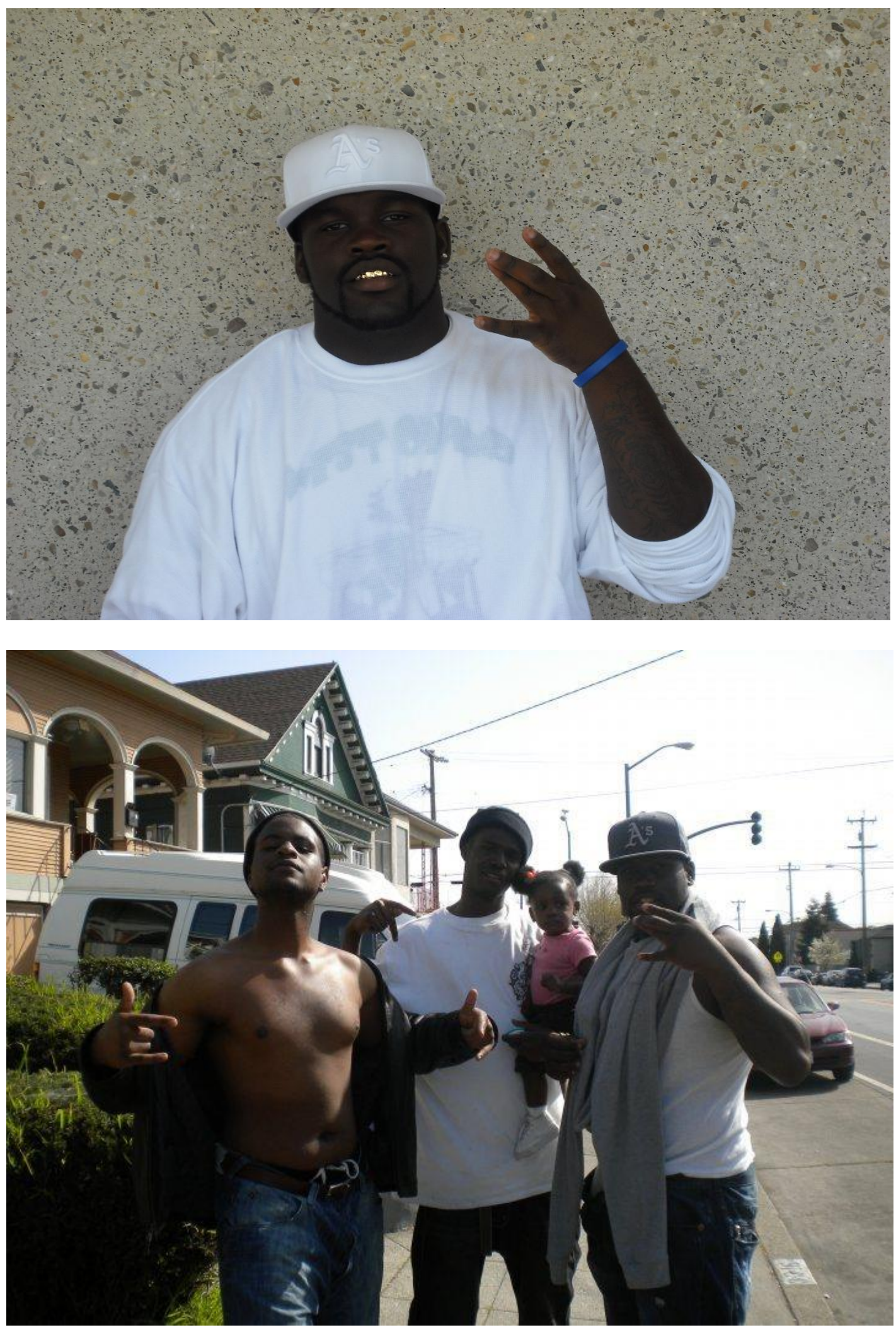


\section{Thug Life: Foundation for MOB Community Based Programming}

\section{Letter to Tupac Continued:}

Pac, based on all of the madness that I have dealt with in my education, life and professional career, I started an organization called My Other Brother (MOB) that works with First Generation College Black students to mentor Black youth of the hood. Black males make up the majority of students in this organization. Students in my organization have expressed that the organization means community, authenticity (being able to express who they are in respect to race and culture) and militancy to them. Last week we had a MOB meeting of which we compared what students are saying about MOB, to the codes of the Thug Life that you, Mopreme and Mutulu constructed. We know that Thug Life served as an intervention in the 90s, a new type of Black power that focused on the tough gritty street code of ethics in connection to codes of militancy, community/solidarity, racial pride and authenticity found in the Black panthers (Shakur, 1992). I knew that it was important for you to keep up with the Black Panther traditions that your mother Afeni taught you while functioning in a different type of Black community of the $80 \mathrm{~s}$ and $90 \mathrm{~s}$ of which the street thug came in to existence for survival as Black men.

In keeping up with the traditions of racial pride, community, toughness (militancy), and authenticity as strengths: If the individuals that were telling me to code switch and "play the game" are leaders, then how come they can't organize young Black men and women the way that I can? What is it about them that is not legitimate in the eyes of the youth? What is it about me, about MOB, about Thug Life, that is legitimate to our young Black males from the hood? And if we are legitimate in impacting students, 
why does the institution make it hell for a Black man like me to thrive? While those that are deemed illegitimate by the masses (Black youth and the community), are rewarded and serve as faculty and staff that hold director positions that target the very youth that they cannot even relate to nor care about?

In respect to the My Other Brother (MOB) organization that I hold leadership over, the term My Other Brother was first coined by Felix Mitchell of Oakland in the 80s as a notorious street entrepreneur organization. Since the death of Felix Mitchell in the 1980s, MOB culture in general has been the prevalent hood' street culture in Oakland that has the ears and eyes of our youth. Oakland hood' leaders such as Marc Anthony Candler (MAC) of West Oakland-Acorn, most contemporarily have continued to drive unity amongst Blacks of the hood in pushing for community, knowledge, discipline, racial pride and Blacks policing their own communities through his Hustlanity MOBISM framework. Felix Mitchell was killed in 1986 and MAC is currently in Prison due to antiBlack trumped up chargers against him and his MOB Team. MOB in peace to Felix and Free MAC and all of the soldiers.

In regards to my MOB organization, we do not partake in the same entrepreneur programming that have been alleged of Felix and MAC. Instead, we are a college access based community organization that pushes the same Black unity and structure found in Felix Mitchell's and MAC's MOB. Of which Felix himself, just like MAC, and just like you Tupac, was influenced by the Black Panthers of the 1960s/70s. My objective and work, given that I am under the MOB umbrella in respect to my West Oakland hood' roots; is to package $\mathrm{MOB}$ as an educational intervention for Black males aimed at utilizing MOB strengths of structure/organization, family, identity development, 
community, cultural and racial pride to impact Black males in educational spaces and life.

The type of Black males that programs are afraid to target for outreach (the students that get kicked out of school and suspended today just as my patnas were pushed out back in the day) are the types that we have been able to engage within the MOB program. I will continue to be a real model, as you mentioned Pac, in building for a generation of Black youth that are looking up to me. These youths are smart, the institution is just racist and cannot retain and engage them. MOB is left to do the dirty work in serving these students by helping them utilize their racialized, community and cultural values as strengths to empower students. I thank you once again Tupac Amaru Shakur for diagnosing Thug Life as the framework that drives the practice of MOB.

\section{Purpose of Study}

Based on 4 years of MOB programming now, the basis of this study is to measure what all this work means to Black students that are part of this organization. In what ways, if any, has the programs focus on racial justice, solidarity and pride assisted students as they attempt to navigate spaces and practices of alienation? Before we can answer this question, it is first necessary to further contextualize Tupac's relevance to this study. Here, we must turn to the title of this study: Strictly 4 My N.I.G.G.A.Z. This title comes from an album released by Tupac in 1993 under the same title. For this album, Tupac utilized the term "nigga" as an acronym meaning: Never Ignorant Getting Goals Accomplished. There are two key inferences that must be made here. First, Tupac is articulating a political project not simply in solidarity with, but as originating in and entrenched with the oppressed Black masses - or in to borrow the language of Walter 
Rodney, Tupac is "grounding." Secondly, with the acronym that's objective is to accomplish, he is proclaiming a political praxis that is on the terms of the Black masses.

Now it should be abundantly clear how and why Tupac is so crucial to this study. He is articulating a particular understanding of racial pride. It is a racial pride and identity development that is defined by, and on the terms of the oppressed Black masses from predominate working -class and low-income communities. And with his conceptualization of "getting goals accomplished," Tupac is defining a notion of success that counters many advertised by academics. In other words, success is defined by the people. In these ways, Tupac enables us to analyze some aspects of Black cultural practices that others may deem pathological.

With this in mind, this study explores how students in the MOB program are impacted by the practices within the MOB program and why these practices are important. The objective of this study is to make meaning of 12 first generation college Black male student experiences in the MOB program and contextualize the outcomes based on their experiences. Speaking of outcomes, this study connects student experiences in the MOB program to tenants of Black Power such as racial pride, community/solidarity, solidarity and community that is embedded in Thug Life as a function of Black male success.

\section{Justification}

Literature on Black male retention demonstrates that Black males experience discrimination at the college level. In a national survey of student engagement consisting of 844,000 respondents, the survey found that more than two-thirds or $67 \%$ of Black men who start college do not graduate within 6 years (Harper, 2006). Respondents indicated 
that encounters with racism and stereotyping from majority white faculty and staff in the classroom as well as other functions of the college institution contribute to students having imposter syndrome and feeling like they do not belong on campus (Harper, 2013). As a counter to this deficit, Black male faculty/staff in higher education validate the racialized experiences of Black males to positively impact their sense of belonging on campus and their persistence in college (Harper, 2013). In addition to race, literature also discusses the important role that culture plays in impacting Black male student retention. Incorporating Hip Hop pedagogy into a traditional campus programming and instruction is critical to engaging Black men and men of color on campus. Hip Hop is a culture that reflects the lived experiences, hopes, struggles, and aspirations of urban Black youth (Andrade, 2002).

The above literature is important as it demonstrates that faculty and staff members must be able to address the complex nature of race and culture (Culturally Relevant Pedagogy) when working with urban Black male students. In expanding on how important race and culture is to empowering Black male students from a pedagogical perspective; it is important to name that much of this literature primarily centers culturally relevant pedagogy in a classroom instruction or campus programming context. This approach undermines the strengths of Black hood cultural capital and student racialized experiences as a tool in navigating all aspects of higher education and life. Akom spoke of this significance of privileging Black hood cultural capital as a life praxis by conveying how mapping processes of racial subordination should be part of a collective, normalized global goal to impact worldwide Black emancipation (Akom, 2006). 
In alignment with Black emancipation, This MOBISM study is critical in exploring new perspectives of cultural wealth and expanding the scope beyond a pedagogical focus. In connection to Black male engagement and identity, this study ties race, culture, community, racial pride and racial justice together in fostering Black male identity (both inside and outside of the college campus or classroom) as a strength. This study is justified as there is a need for more research that looks at Black males countering respectability politics and code switching through Black male strengths of solidarity, community, racial pride and authenticity in culture. These strengths are why Thug Life is important for all Black males and all community members to understand, resonate with, and be empowered to live into this identity as opposed to only utilizing this pedagogically. 


\section{Chapter 2: Theoretical Framework and Literature Theoretical Framework: T.H.U.G. L.I.F.E.}

Although MOB is a program at an academic institution, MOB's success as a program cannot solely be understood in the traditional standard of academic achievement. While academic achievement is an outcome and students do reach academic/traditional success through forms of resistance: MOB's focus centers around issues related to identity and consciousness. Likewise, this study is not about measuring academic success, it is about how students experience and resist racialization and the interventions that $\mathrm{MOB}$ provides to these experiences. In this respect, academic success outcomes that were found in this study must be placed in context with how students resist racialization.

It just so happen that the confidence students have built to resist racism by being affirmed in their urban Black male identities found in this study: Was also a confidence that reflected how these authentic hood Black males (who expressed themselves in a way that is counter to Eurocentric norms and values) were also the kids on campus getting A's and Bs and serving as leaders on campus. In this case, while academic achievement is an outcome for these students, their processes and experiences of racialization is the focus in measuring their success in MOB. Measuring success the MOB way, the Black masses way: Is to celebrate the Black man that uses his political racialization to "bang on the system" while still achieving academic success within that same system as praxis to change the system through education.

Moreover, to also celebrate the Black man that says "fuck the system and fuck school" and choose to not want to engage within the system at all-and instead focus their energy on creating their own Black system. The main focus in both these cases, is that 
these students are navigating their experiences of alienation in a way that is authentic to their own meaning making systems that is grounded in the urban Black community and culture that they stand from. Whatever produces from this above stated grounding, is whatever produces.

Because MOB is a program that is rooted in the experiences of urban Black males, the program aligns itself with many of the principles espoused by Tupac Shakur. These principles are central to the work of the program itself. In order to adequately measure how the program utilizes these principles in helping students navigate processes of racialization, this dissertation uses a new set of concepts related to Tupac Shakur's development of T.H.U.G. L.I.F.E. These concepts allow me to explore and make sense of the experiences of MOB students.

The Hate U Gave Little Infants Fucks Everyone (T.H.U.G. L.I.F.E or Thug Life) framework of Tupac Shakur within Hip Hop in particular, is a new type of Black cultural capital that instills confidence, racial pride, and resiliency in Black people to utilize their struggles as a source of empowerment that allows them to navigate life against all odds (Shakur,1992). Black males identify with Thug Life as it means the hate that has been bestowed upon Black men as young children seeds of oppression, will eventually blow up in the faces of colonial systems (Shakur, 1993). Shakur further conveys that a thug is a person who comes from rough conditions and who is oppressed, that still rises above to empower themselves against oppressive power structures (Shakur, 1993). In connection to community cultural wealth (Yosso, 2005), Thug Life is embedded in forms of communal, familial, cultural and resistant (protection of Black community members) capital nurtured through the code of Thug Life for Black men and women. 


\section{Thug Life as a Conceptual Framework}

Thug Life as a Conceptual Framework; Stages of Consciousness

$\begin{array}{ll}\text { They don't give a fuck about us } & \text { Recognition of inequality/individualized }\end{array}$ racism and dehumanization

\section{Guess It's Cause We Black That We Recognition of a community of the \\ Targets}

oppressed

\begin{tabular}{l|l} 
Conquer the Enemy Armed With & Recognition of communal \\
Education & struggle/solidarity
\end{tabular}

Never Ignorant Getting Goals Accomplished

Political praxis rooted in racial alienation:

MOBISM

There are four key concepts that I have developed related to Thug Life. These

provide an opportunity to understand the experiences of MOB students with nuance and depth. Below I provide a conceptualization of each of these concepts. In this study, I use these concepts as a framework to do a discourse analysis in which I am looking for these themes in the data.

\section{They don't give a fuck about us}

(Recognition of inequality/individualized racism and dehumanization)

One theme that emerged from the data was student recognition of racism. Several students expressed frustration over feelings that they were frequently subjected to racial discrimination. These sentiments are captured in the Tupac song, "they don't give a fuck about us." In this song, Tupac describes the racial oppression that Blacks are confronted 
with on a global scale. I use this concept to describe a beginning stage in the development of consciousness when students realize the discrimination that they face based on their Blackness. Students describe a process of understanding the reality of what they must face as Black people. This experience with racism often follows them to campus. Although during this stage, students often speak of individualized experiences of racism, such as "I" and "me," they begin to make connections between individual and collective experiences with racism. This understanding is captured in the Tupac phrase "they don't give a fuck about us.”

\section{I guess it's cause we Black that we targets}

(Recognition of a community of the oppressed)

In this stage, students make clear connections with their personal experiences with racism to structural forms of domination. For example, students begin to realize that they are part of a community of others that share a common experience with racism. In this stage students often use words like "we" and "us" when speaking about racism. These sentiments are captured in the Tupac song, "letter to the president;" in particular, the line from the song "I guess it's cause we Black that we targets." In this line, Tupac describes the racial oppression that Blacks face on a systematic level as a community that experiences this shared struggle. I use this concept to describe a another stage in the development of consciousness when students realize the discrimination that they face based on their Blackness on the individual level (personal experiences with discrimination on campus and in the real world outside of campus), are experiences that Black men face as a collective. Students describe a process of understanding that they are part of a community of Blacks that experience discrimination. This experience with 
racism often extends beyond the college campus. Although this is a stage where students often speak of experiences of racism as a community, such as "we" and "us," they also begin to develop a sense of pride in this collective struggle and begin to gain a consciousness,- a Black identity, that is grounded in their community struggle. This understanding is captured in the Tupac phrase "I guess it's cause we Black that we targets."

\section{Conquer the enemy armed with education}

(Recognition of communal struggle/solidarity)

Solorzano utilized methods of qualitative inquiry and counter storytelling to examine the construct of student resistance through her Latino/Latina critical race theory framework (Solorzano, 2001). In the "conquer the enemy armed with education" stage, students begin to identify the need to resist collectively against the forms of racism that they have identified. Students begin to develop a collective sense of pride in the same cultural attributes that they are often chastised for. In other words, students see their Blackness as both tying them to a community of the oppressed and as an archive for resistance. During this stage, students begin to identify the need to educate themselves in order to resist the racism that they are facing. These sentiments are captured in the Tupac song, "words of wisdom;" in particular, the line from the song "conquer the enemy armed with education.” In this line, Tupac defines education as knowledge of self/culture and the historical struggle that Blacks face as a collective. Tupac uses education as a political praxis to establish collective Black pride, grounded in collective Black struggle, to resist oppression. I use this concept to describe a stage where students development a consciousness to use their education to resist aspects of discrimination by constructing 
solutions to their collective Black struggles. This understanding is captured in the Tupac phrase "conquer the enemy armed with education."

\section{Never Ignorant Getting Goals Accomplished} (Political praxis rooted in racial alienation: MOBISM)

In this stage of development students begin to engage in political praxis rooted in their sense of pride in being Black. Students have recognized their shared experiences with racism, have expressed a collective affirmation in their Blackness and have made a commitment to resist the structures that they have identified. These sentiments are captured in the Tupac phrase, "N.I.G.G.A: Never Ignorant Getting Goals Accomplished." In this phrase, Tupac has expressed a political praxis that is grounded in pride in collective Black struggle-producing an individual and collective commitment to resist discrimination in a way that is for the Black community and by the Black community. I use this concept to describe a stage where students development a consciousness, an eternal commitment to justice by the means of whatever justice looks like to the collective Black community and themselves as individual members of that community.

Whether it be students' commitment to engaging and building with the urban Black youth, wanting to be part of and/or lead a revolution, or utilize their Black pride to resist discrimination in their personal encounters in school/life: Their justice aspirations are completely grounded in their own meaning making systems in alignment with the collective oppressed Black masses. This understanding is captured in the Tupac phrase "N.I.G.G.A: Never Ignorant Getting Goals Accomplished." Dyson conveyed the term nigga in connection with Thug Life as a praxis to judge and critique the anti-Black society that constructed the term nigger in the first place (Dyson, 2006). The phrase "Nigger," is a term used to insult Blacks and push a subservient identity that is under 
White coloniality. "Nigga," in contrast, is the Black counter term to Nigger that is embedded in Black pride and empowerment in a collective struggle to overthrow the very institution that created the term Nigger (Dyson, 2006).

MOB helps to facilitate these stages as it provides a space for students to reflect critically on their shared experiences. In connection to counter storytelling to examine the construct of student resistance (Solorzano, 2001): Resistance in this study is defined as students resisting whiteness by privileging Blackness via how students show up as their authentic Black selves via dress apparel (in a way that counters white norms), how they resist racist experiences in school by continuing to persist and assert themselves in racist encounters on campus in a way where they refuse to be shut down academically; furthermore, resisting whiteness by creating programs that engage the larger Black community by working with Black youth in a way that is authentic to them-without any regard for how the institution thinks they should function. Each of these key concepts are central to Tupac's Thug Life framework and form the foundation of my analysis. Each of these concepts operate within the framework of a political philosophy and praxis that is rooted in the experiences of the oppressed Black masses.

It is important to understand that these themes operate in a context that is "strictly for my niggaz." In other words, solidarity with the Black masses is the defining feature of each concept. What is key here, is that Tupac is mapping a political philosophy that articulates a notion of justice, success, identity and solidarity that is in accordance with one's own worldview. In other words, success is not defined from the outside, again, this is a key departure from Eurocentric notions of Black life. This will allow us to interpret the experiences of students within MOB in a different light. 
Aspects of the code of Thug life convey that Carjacking in the hood is against the code, selling drugs to children is against the code, slanging drugs to pregnant Black women is against the code and having children of the community sell drugs is against the code (Shakur, 1992). Other codes hold that the police do not control anything in the Black community and instead the community does (Shakur, 1992). Furthermore, those who live the code of the Thug Life must make the community safe and protect it at all times (Shakur, 1992). These key elements of Thug Life are rooted in themes of community, racial pride, solidarity and a sense of protection/militancy against oppressive forces such as the police as a function of racial justice. Thug Life as Tupac Shakur conveys, reflects Black experiences with racism and oppression as a means to counter colonialism and survive (Shakur, 1992).

\section{Literature}

This work explores the experience of MOB students with racialization and attempts to highlight the forms of resistance that these students have developed. In this way, this study differs from most studies on college retention programs. Although some studies acknowledge that students face racism, their primary concern is on the program itself, not on the process of student experiences with racism. This study explicitly explores this process. It attempts to analyze the ways students both experience racism and develop strategies to navigate that racism. I focus on how MOB serves as a tool for students to deal with these experiences.

The problem with much of the literature is that it focuses on academic success and not on this process. Therefore, much of the literature is not sufficient for understanding how students develop a critical consciousness. In other words, a student could say "fuck 
school." Much of the literature would understand that as academic failure. However, there is something more nuanced happening and in order to see what is happening we need to develop a new framework. That framework is provided by Tupac Shakur.

In connecting this larger issue of racism to Black male engagement and retention, the Thug Life framework is critical to addressing the problem of anti-Black male identity. Thug Life, as mentioned above, is an anti-deficit narrative of culture and power that must be tapped into to impact Black male success. Existing literature on what leads to Black male departure in higher education and what engages Black males on campus to impact their success surrounds themes of Black male identity focusing on the following: Racism, racial affirmation, and cultural validation in relation to what impacts Black male sense of belonging and engagement on campus.

\section{Racism and Black Male Educational Experiences}

There is much literature that discusses the impact that racism in the college institution has on Black male student attitudes, experiences and retention in education (Harper, 2006). Black males experience discrimination in the classroom and have negative attitudes towards education and school importance especially when there is no sense of racial centrality (educational material and practices that are centered around their racialized experiences) in their education (Chavous, 2008). In examining the influences of school racial discrimination and racial identity on academic engagement outcomes for Black adolescents, Chavous examined relationships among racial identity, school-based racial discrimination experiences, and academic engagement outcomes for adolescent Black boys and girls in Grades 8 and 11. Methods included 410 African American adolescents (n 204 boys and n 206 girls). Findings demonstrate that centrality moderated 
the relationship between discrimination and academic outcomes in ways that differed across gender (Chavous, 2008).

Findings further convey that girls had significantly higher 11th-grade GPAs and academic self-concepts than did boys. However, the Boys in this study reported more classroom and peer discrimination (Chavous, 2008). For boys, higher racial centrality related to diminished risk for lower school importance attitudes and grades (Chavous, 2008). This data is important because it emphasizes how racism and affirmed racialized experiences is an important factor in Black male outcomes for better or worse. Black males facing racism and discrimination from the education institution results in low attitudes towards education. Yet, when their educational experience centers on their racial identity and experiences (racial centrality), lower school importance attitudes are diminished (Chavous, 2008).

In connection, Shaun Harper looked at Black male experiences with discrimination at the college level in addition and explored themes of racial centrality via Black males being validated in their identities and lived experiences (and the implications for this) in a quantitative study. In a national survey of student engagement consisting of 844,000 respondents, the survey found that more than two-thirds (67 percent) of Black males who start college do not graduate within 6 years, -the lowest completion rates among both sexes and all racial groups in higher education (Harper, 2006). Respondents indicated that encounters with racism and stereotyping from majority white faculty and staff in the classroom and other functions of the college institution contributed to students having imposture syndrome and feeling like they do not belong on campus (Harper, 
2006). Methods featured a report from 50 PWI's on Black male experiences and retention.

In continued findings, many Black male student survey responses conveyed that Black males had to contend with feelings of alienation, isolation, racism, discrimination and environmental incompatibility (not able to relate or have a real connection to the campus) (Harper, 2006). Based on findings from the study, harper implied that institutions need to maintain affirmative action and race based college admissions policies (Harper, 2006). Furthermore, institutions must invest in more ethnic based programs such as Gear Up and hire more Black male faculty and staff to validate the racialized experiences of Black male students on campus (Harper 2006). This literature is significant because it looks at the general problem of Black male retention based on the numbers as well as a glimpse of the experiences that Black males face that impacts their retention. Like the Chavous study, findings from Harper's study indicates that racism and Black males not having their lived experiences affirmed on campus results in less engagement on campus for Black males and subsequently low graduation rates. In combatting this victim narrative, Black male racial centrality (having their racialized experiences affirmed via campus programming or faculty and staff) impacts their success in a positive way (Harper 2006). These implications, again, applies and can be traced back to Black male experiences at the K-12 level.

Through semi structured individual interviews of Black high school student experiences in a Youth Participatory Action Research Program (YPAR), Elan Hope examined how Black high school students understand issues of racial discrimination and inequality in their schools. Through semi-structured individual interviews conducted 
early in the program, eight students (including 6 Black males) recount experiences of racial stereotyping, discrimination from teachers and staff, lack of institutional support and lack of racial diversity in curricular offerings (Hope, 2014). Findings reveal that student interactions with teachers play a pivotal role in the development of achievement and social competence (Hope, 2014). This is critical as it conveys how teachers, faculty, and administrators in K-12 and higher education serve as key agents of school-based racial socialization. Directly related, Black youth receive messages about what it means to be both Black and a student through their interactions with their teachers (Hope, 2014). Students from each school district indicated at least one personal experience in which a teacher or school staff member treated them unjustly based on race. The above literature looks at themes of racial discrimination, alienation and negative stereotyping that has been a problem that Black males face in K-12 and higher. However, much literature also focuses on Black male racialized experiences in both k-12 and higher education from a high achieving anti-deficit lens.

Hotchkins used a qualitative case study approach to explore how African American male collegians embody and perform various forms of excellence within a predominantly White college institution (PWI). Data was collected using three semistructured interviews, a brief in-person follow-up interview, and three observations of participants on how they contextualized the resulting interview data. Hotchkins found that participants' experiences with anti-Black racism fostered higher ordered critical thinking, resiliency, and a reinforced commitment to social justice via collegiate excellence outcomes (Hotchkins, 2008). While this literature looks at student experiences from an anti-deficit framework emphasizing a positive narrative of resiliency based on 
encounters with racism, it is still connected to the above literatures in that it focusses on Black males racialized experiences in higher education that impact their educational outcomes and retention.

Harper, Hotchkins, Hope, and Chavous looks at Black male student experiences and factors such as racial discrimination amongst educators. In alignment, William Tierney looked at functions of the higher education institution and implications for not validating Black male identity in connection to departure and low retention rates of students. This study was intentional in holding that Vincent Tinto's theory of college student retention misses the mark for minority students, Black males in particular (Tierney, 1999). In utilizing program observations and student narrative interviews on Black student experiences in a college prep based program; Tierney's study featured a 3year program evaluation that focused on student experiences with a college preparation and retention program (NWI) that served high school students from inner-city South Central neighborhoods and supported students through college.

Tierney maintained that Vincent Tinto's theory of college student retention misses the mark for minority students by holding that students must assimilate to the dominant cultural mainstream and abandon their ethnic identities to succeed in predominately white Colleges. Findings from this study demonstrate how students specified that the cultural and community validation from the program had the strongest impact on student confidence to persist in higher education (Tierney, 1999). Based on findings, Tierney conveyed that instead of students of color at PWI's undergoing initiation rites that lead to their cultural suicide: Cultural Integrity, a cultural model of academic life that affirms who they are, instead of rejects, would have a profound impact on students' retention and 
success as they are validated on campus (Tierney, 1999). There is much literature that looks at models of academic life that affirms who Black male students are, in respect to culture and race, to impact their engagement and retention on campus.

\section{Race: Validating Black Males Lived Experiences}

Harper looked at Black male issues of racial discrimination in higher education and how Black males have resisted discrimination and found belonging on campus to impact their retention. Harpers study is significant in that it focuses on Black males who succeed in higher education in contrast to much existing literature that looks at Black male problems in higher education that result in low graduation rates. In this research, harper conducted interviews with Black male achievers at 30 predominantly white colleges and universities.

Findings reveal that students were frequently confirmed with stereotypes but overcame them by partaking in leadership roles, engagement in student organizations (Black organizations and spaces for ethnic minorities) (Harper, 2012). Findings also convey that Black faculty/leaders on campus serve the purpose of empowering Black students to resist stereotypes on campus. By doing so, this affirms students to resist and counter their negative experiences (Harper, 2012). Example, one student explained that being able to engage with other Black male faculty/staff on campus who could resonate with their struggles empowered students to feel confident in challenging campus peers and professors whenever students are subjugated to racial stereotypes. In connection with the literatures discussed thus far, this data provides an understanding that when students do have a connection to campus, it is when their racial and cultural experiences are validated by faculty and staff programming that empowers them to persist. 
Brooms further explored this racialized and cultural validation that empowers Black males in his study of Black male experiences in the college Black Male Initiative (BMI) Program. In the multisite study, he explored the impact of the BMI program on Black Male students college experiences across three separate campuses. As theoretical frameworks, he used Yosso's community cultural wealth and Strayhorn's belonging models to investigate how the participants made meaning from their engagement with the program (Brooms, 2018). Findings explained how the BMI program enhanced the students since of mattering and belonging on campus through helping them access sociocultural capital, providing holistic support focusing on Black male identities and engendering student persistence (Brooms, 2018). This is important in naming race, in connection to campus programming, as an important factor to providing holistic support for Black males rooted in Black male identity. Based on the discussed literature, race is important. Further existing literature connects culture and cultural relevant pedagogy as a factor in validating Black male identity by engaging students in a way that validates their lived experiences in the educational space to impact retention.

\section{Culture: Validating Black Males Lived Experiences}

Andrade used Hip Hop as a tool to engage urban Black and Brown youth, allowing them to make meaning of who they are and take ownership of their education by incorporating hip hop in classroom instruction. To study the impact Hip Hop culture has on the identity development of Black male and Latino students, his study utilized qualitative methods (classroom observation) in observing a classroom unit designed to incorporate Hip Hop music into a traditional style of English poetry. Findings from this study suggest that not only were students engaged by being able to incorporate their lived 
experiences and positionality (via Hip Hop) to the mandated curriculum/text; but students were able to have fun and learn about a culture and genre of music of which they had great familiarity with (Andrade, 2002). In connection with culture that Tierney discussed, incorporating Hip Hop in educational spaces allows educators to think outside of the box and tap into the worlds of Black male youth in order to make powerful connections with traditional academic texts and affirm, in meaningful ways, the everyday lives of Black males (Andrade 2002). This study is significant in that it sets a foundation, in connection to culture, for what works in validating students in spaces.

The term reality pedagogy was coined in using Hip Hop cyphers to create a learning environment in class that allows Black students to bring their knowledge, perspectives and systems of meaning-making to understand course material (Emdin, 2011). Emdin used Hip Hop/Rap Cyphers to allow Black students to bring materials and knowledge from their surrounding communities to their science class experience. There is much literature that looks at the significance of using Hip Hop in teaching strategies to affirm the lives of Black youth and to develop learning and critical thinking abilities for students. Cooks discussed the importance of using Hip Hop in the classroom as a teaching tool in his study on middle school Black males in the Oakland Unified School district. Utilizing Hip Hop in the form of rapping is an important tool for instructional strategy to impact student writing/literacy, voice and their overall validation as young Black males (Cooks, 2004). Hip Hop pedagogical framework, frameworks rooted in cultural relevant pedagogy in general, impact both K-12 and college stakeholders in how to utilize the cultures of Black youth to impact student success (Howard, 2003). Andrade and Cook's study conveys that Hip Hop culture is one approach to validate Black male 
student identity and culture. Howard expressed that faculty and staff members must be able to address the complex nature of race, culture, and ethnicity when working with student populations (Howard, 2013). Furthermore, those who work with students regardless of racial background must understand the racial and cultural context of students and be especially intentional when working with Black students at the K-12 and college level (Howard, 2013). Akom further discusses how critical it is to center students culture and racialized experiences within their learning by using Hip Hop as a form of liberatory praxis within classroom instruction (Akom, 2009).

Nasir explored aspects of culturally relevant pedagogy in her study of $9^{\text {th }}$ grade Black male student experiences in an all-Black male manhood development class. In his study, methods draw on classroom observations and interviews with twenty-three Black male ninth graders in an urban district to focus on the nature of disciplinary practices in an all-Black, all-male manhood development class. The Study found that the disciplinary practices in the class were rooted in a Black cultural way as opposed to demonizing Black male students by judging their behaviors as threatening via school suspension and disciplinary referrals (Nasir, 2013). Based on findings, Nasir argues that, led by a "hero teacher," the manhood development class functions as an example of "transformative resistance" in changing how Black male students perceive themselves rooted in their racialized, community and cultural experiences (Nasir, 2013).

\section{Gaps in Literature: What Tupac Conveys}

Tupac agrees with transformative resistance and empowering students through their culture and racialized experiences as discussed in the above literature to impact student success. The literature already highlights the significance of taking students lived 
experiences (issues of racism, internal racism within the community, poverty, and strengths such as Hip Hop etc) and centering them at the forefront of students classroom experiences to engage them. Tupac conveys that this engagement and sense of empowering students through race and culture should be taken to the streets, schools, the workplace and essentially all fabrics of society beyond the school. In order to do so, it would not only be the effort of educators to empower students via classroom CRP practices; it would be educators, community and students empowering each other as a collective in the fight for the liberation of Black life. The "culture," for the Black masses is a culture of resistance.

When schools fail urban Black males, it results is the direct outcome of the school to prison pipeline and prison industrial complex. There is a strong relationship between school suspension and incarceration rates (Fryer, Heaton, Levitt, \& Murphy, 2013). In this case, the achievement gap continues to be a source of focus of many CRP scholars. Tupac helps us understand that schools are not failing Black boys, and instead they are working as design to push Black males into prison or to push a Eurocentric conformity amongst Black youth. As such, Tupac calls for a lifestyle and culture of practice that addresses the government, judicial system, education system, and the police overall as they serve to enforce the school to prison pipeline.

When we analyze these above phenomena through a THUG LIFE lens we can see that the key factor is that the knowledge and practices of Black youth should be first and foremost understood through their own experiences. Below, I provide more discourse analysis of Tupac lyrics in order to demonstrate his conceptual utility. "My heaviest words will move a mountain 
Casualities in mass amounts (*political praxis rooted in racial alienation*), brothers keep countin

Fuck the friendships, I ride alone

Destination: Death Row-finally found a home (*Recognition of community of oppressed*),

Plus all my homies wanna die; call it euthanasia

Dear Lord, look how sick this ghetto made us (*Recognition of community of oppressed*)

Sincerely yours, I'm a thug (*recognition of communal struggle/solidarity*). The product of a broken home

Everybody's doped up, nigga what you smokin on?

Figure if we high they can train us

But then America fucked up and blamed us

I guess it's cause we Black that we targets (*recognition of community of oppressed*) My only fear is God, I spit that hard shit

In case you don't know, I let my pump go

Get it ride for Mutulu like I ride for Geronimo

Down to die for everything I represent

Meant every word in my letter to the president (*political praxis rooted in racial alienation*)"

(Shakur, 1996).

In connecting all discussed literatures together surrounding Black male sense of belonging/engagement in connection to Black male retention: The literature helps us 
understand how important validation of racialized experiences and culture is to Black male identity. It is that thing that needs to be validated as part of the process of Black males being engaged and finding belonging in educational spaces to impact their retention. Overall, the literature divides identity into race and culture such as need for more Black faculty and staff to validate Black students (Harper, 2013) or the importance of faculty and staff of all racial groups to understand the cultures of Black youth and how to use this in teaching instruction to validate students (Howard, 2003). However, this position assumes that anyone of any race can have the same impact on Black students as long as they practice understanding student culture and be intentional when working with them. Or, it assumes that so long as Black males have Black faculty and staff (racial focus) they will have an automatic connection with the faculty. Which we know this is not always the case.

Even in the case where we have a Black faculty or staff member that also utilizes culturally relevant practices (CRP) in their work with students, the literature suggests they are primarily using CRP in classroom instruction pedagogy or campus programming for students to implement culture in learning. Yet, in this same context, some of these same educators are still telling students that they have to "code switch" once they leave those educational "safe spaces." Essentially, and perhaps unconsciously, sending a message to students that they must abandon the very cultural roots that are affirming to them in school educational spaces when engaged with CRP practices once they leave the campus and navigate the larger society.

Code switching typically is associated with some sort of image/appearance or behavioral semantics of the student that must be "molded" or shifted in order to "fit" in 
institutions, and less to do with the work and content of the student. Furthermore, connecting back to CRP, existing literature highlights CRP practices often in alignment with Black male achievement gap to impact Black male retention in the school primarily. While the achievement gap is important, primarily focusing on the achievement gap for Black males do not speak to the overall historical experiences and realities that shape Black male students outside of school regarding systematic racism. Furthermore, respectability politics is not praxis for taking up forms of justice against the institution. Instead, code switching, respectability politics, privileges the institution. Tupac helps us understand that a sense of solidarity amongst Blacks, pride in culture and identity, and affirmation of racialized experiences as a lifestyle, privileges Black males to resist politics of respectability. Thus, creating success by their own values and standards. “It's time for us as a people (*recognition of community of oppressed*) to start makin' some changes

Let's change the way we eat Lets change the way we live And let's change the way we treat each other You see the old way wasn't workin' So it's on us to do what we gotta do to survive (*recognition of communal struggle/solidarity*)" (Shakur, 1998).

In analyzing the body of literature through a Tupac Shakur lens, this study adds on to scholarly work that centers on the significance of race and culturally relevant practices to empower urban Black youth. This study explores new perspectives of 
cultural wealth centered on the role that Black male students and the Black community overall play in utilizing their individualized and collective experiences of inequality/discrimination to build a sense of pride and solidarity to impact success: a political and cultural praxis that is rooted in their racial alienation. In order to investigate what cultural wealth looks like to students through their experiences in the MOB program, we asked students what does MOB mean to them?

\section{Research Questions}

This project aims to explore the racialized experiences of young Black males. In particular, my interests lay in the ways in which young Black males experience schooling as a process of alienation, the ways in which they navigate these processes, and what role programs that embody the solidarity, racial justice, community/solidarity and racial pride identity, philosophy and practices of Tupac (can) play on helping students navigate these experiences. Undergirding this interest is a deep concern for how these students live their Blackness and how these spaces of alienation can be mitigated in a manner that leaves this Blackness intact.

In essence, this work simply asks: What does MOB mean to Black male students in the MOB program? 


\section{Chapter 3: Methodology \\ Recruitment and Selection}

To examine how Black males are impacted by community/solidarity, racial pride and racial justice in navigating processes of alienation, this study featured 12 currently enrolled California State University, East Bay (CSUEB) male students within the MOB program, who self-identified as Black and First-Generation College students from lowincome communities. The study emphasized a mixture of lower-performing, middle performing, and high achieving Black males as measured by GPA. Lower performing are students that are below a 2.3 GPA, middle performing students have between a 2.31 and 2.99 GPA, and high achieving students were identified as having a 3.0 or higher GPA. Interview questions were used to explore student experiences within the MOB program, assessing what MOB means to students in connection to identity, culture and student development.

\section{Research Design}

This study was designed as a program evaluation, of which we utilized an auto ethnographic approach of storytelling, narrative, self-reflection, and testimony to measure the effectiveness of the MOB organization and the impact that MOB has on Black male student participants. Data was collected in the form of video recorded interviews: 12 semi-structured interviews that took place for approximately 15-30 minutes. Interviews were video-recorded and transcribed verbatim. Out of the 12 participants in the interviews, 3 participants in this study did not respond to the interview question on camera; these 3 participants chose to have their interview response in a written narrative format on paper. 


\section{Context of Study}

All 12 student interviews in this study were conducted at CSUEB campus in a reserved classroom. The 3-part coding and data analysis process involving myself and students took place in this same classroom the following week after completion of student recorded interviews.

\section{Participant Selection}

At the start of the study, I sought to interview all college student members of the MOB community organization, which serves as a student club at CSUEB. All MOB students interviewed in this study were undergraduate students at CSUEB during the time of the interviews and all recognized official student members within the MOB community organization. To examine student experiences in the MOB program and MOB's impact on students, I used a video recorded and written narrative interview method of which student participants responded to the open-ended question: What Does MOB Mean to You?

\section{Positionality: Relationships with Participants}

I have known each of the participants since the start of the MOB organization in January of 2016. Furthermore, I had already known some students years prior to the start of MOB as I served as students' academic counselor at CSUEB in the EOP program. During this time, most of the students were freshmen, second year or third year CSUEB students within the MOB program. As such, it was a rewarding experience to begin 
collecting data for this study in Spring 2019. By this time, these same MOB students that began with me in Winter of 2016, had graduated that Spring 2019 semester from CSUEB, or were now in their senior year at CSUEB and had developed into leadership roles within MOB. Or, students had already graduated and had just begun their graduate school programs or were working in the real world. I knew each student participant in this study ranging from 2 years to 4 years. I have established and continue to maintain close relationships and connections with these students that extend beyond this study. It should also be mentioned that as of spring 2019, we have new undergraduate MOB members. However, I made the decision to not include the new MOB students within this study. I thought it was important to center this program evaluation, this measurement of student experiences in the MOB program, around students that have been in the MOB program for at least 2 years. As such, my original group of MOB students that began in Winter 2016, were the primary focus for the subjects in this study.

\section{Access and Protection of Participants}

I was able to have access to student participants in this study as they are members of the MOB organization, of which I serve as Founding Director for. As members of the organization, students have a variety of roles that they serve in such as "Real Model"Outreach Mentor. Outreach Mentors conduct K-12 outreach in the Oakland, CA. Some students serve as President and officer of the college student club of which they have specific duties. Some students oversee the MOB social media and marketing page and some students are just simply MOB members. MOB members are simply part of the mob family and they benefit from the various programming and services provided by the MOB. In all cases, we have "MOB meetings" once a week of which I have the 
opportunity to meet and program with all students together. Based on these meetings, I asked students if they wanted to take part in this study. With students agreeing, we agreed to dedicate our typical MOB meeting times for the months span to conduct the interviews and data collections and analysis for this study.

\section{Data Analysis}

To measure community/solidarity, racial pride and racial justice (tenants of Thug Life) and how Black male MOB students navigate processes of alienation through their MOB experiences: We conducted our study in the same room on CSUEB campus that we have our weekly MOB meetings at. As we had our normal MOB programming with all 12 students present in our meeting room, one MOB student would go into the next room to be video recorded by another MOB student for the interview. The three MOB students that chose to write their narratives down on paper instead of being video recorded also went to the next room to write their narrative response to the interview question once their names were called. All students knew ahead of time that once they are called to go to the next room, they would respond to the open-ended question, "What does MOB mean to you?" This allowed MOB student participants the opportunity to still be present in solidarity with their fellow brothers in the MOB program and freely express what MOB represented to them based on their experiences in the program. Most critically, students were able to ground their responses with the knowledge that they created along their journeys as members of the MOB program for the past 3 to 4 years. In connection to this approach, we utilized a BEAR framework to analyze and construct data based on student narratives. This allowed us to also incorporate other student data, such as MOB members recollection of the historical development of the MOB program as well as 
documents/pictures from various MOB program activities in our analysis of student experiences in the MOB program

Black Emancipatory Action Research (BEAR) is a research orientation aimed at creating strategies of liberation from intersecting forms of oppression experienced by people of African descent across the Diaspora (Akom, 2011). Since BEAR has roots in critical Afrocentricity and Africana womanist scholarship, it deals with the question of race, gender and other forms of identity from the perspective of Black cultures being centered, located and grounded (Akom, 2011). In this MOB study, Black male student participants coded their own narratives and made meaning of their data around their racialized identities. MOB research study participants took part in a community based, 3part coding process in transcribing and analyzing their own interviews. This process included the following after each student interview was conducted:

1). All student participants first listened/watched each student interview on screen together in CSUEB classroom (same room where weekly MOB meetings take place during academic year). Then, they wrote down on the chalkboard what they felt, heard, and saw from each interview as the interviews continued to play.

2). Students listened/watched all of their interviews for a second round on screen, and went back to the chalkboard to write stars next to the most salient ideas and concepts that they felt and heard in the interviews.

3). lastly, each student picked /circled the three most salient concepts from the interviews that had stars next to them and defined what those concepts meant to them in written narrative. 
4). Both students and I then came together with our most salient concepts that we had wrote stars next to and further defined. Then, together, we came up with the 10 most salient concepts from student interviews that we felt represented what MOB represented to student participants in study based on their interviews. Several concepts were used interchangeably and combined given that students used the same or similar definitions for those concepts.

5). Findings/Salient concepts from interviews were color coordinated and highlighted with various colors to represent each concept/theme from the interview findings.

6). Findings/Salient concepts were also analyzed in connection with MOB members recollection of the historical/foundational development of the MOB program as well as documents/pictures from various MOB program activities in connection with student experiences navigating alienation/discrimination. 


\section{Chapter 4: Findings}

\section{Foundational Stages of MOB}

In chapter two I did a discourse analysis for four critical concepts in alignment with Thug Life that connects to MOB students' experiences with racism and their development of resistance against racial discrimination to impact their success. These stages emphasized, 1) MOB students' recognition of racism/inequality on an individual level; 2) a recognition of structural level inequality of which they are members of a community of oppressed; 3) a recognition of pride and solidarity in communal struggle; 4) a recognition of political praxis to resist structural racism/dehumanization through education. Given that we contextualize the concepts in the findings from this study in connection to the politicization of MOB as a program: It is important to go into the foundational history of the MOB program given that this program was created based on my personal interactions/discussions with students as they experienced these 4 concepts,in real time, based on their experiences as Black men at the college campus and in the larger community outside. I had already built relationships with these students in serving as an EOP Academic Counselor at CSUEB campus prior to starting the MOB program. The racialized experiences that students shared with me in our one on one meetings would turn out to be my foundation for why I pushed-with student support, to get the MOB program rolling to affirm students.

In connection to how students transition through each of the four concepts, one thing I found is that these four stages are not linear. Instead, they are a continuum. Students are reaching all these points/stages at various periods within their MOB experiences. For example, in a conversation a student may share how they were racially 
targeted/discriminated against in a narrative, which is a recognition of inequality at the individual level. And in a different narrative, that same student may discuss how it is fucked up that other Black men go through this same struggle, which is a recognition that Blacks experience oppression at the community level, not just individual.

Students may also discuss how they plan to resist racial inequality all within that same narrative of which they discussed their oppression. This is a recognition of a political praxis rooted in their racial alienation. Many of the conversations during the data collection phase centered around the 4 concepts that students were experiencing which serves as foundational stages of the MOB program. Because of this, the history of MOB was a central part of data because this provides context to the four stages of MOB consciousness found in data. Here I give an overview of the students' recollection of the historical formation of the program in response to the racial alienation that they were experiencing.

As mentioned, I already had a connection with most of these students on an individual level, as I served as their EOP Counselor. Our EOP appointments would focus on academics, class enrollment, major exploration, graduation requirements, and professional development/post undergrad opportunities. Although we touched on personal and racial issues within our appointments, we rarely had a platform to make meaning of Blackness and student lived experiences among a community of peers. I recognized that this was critical because so many students would discuss racial issues with me in our individual appointments. Therefore, creating MOB was huge because it gave an initial platform for this Black exploration and meaning making to be channeled in a larger way via a community of peers to build with. 
The Director of EOP had already been in discussion with me to get a males of color program started within the EOP department to focus on increasing college retention rates for the men of color within EOP. However, our ideas did not align given that she rejected my idea for "My Other Brother-MOB"-holding that the name "MOB" was in association as a gang. She said that MOB was "inappropriate for a college-based program." Her rejection was in alignment with her idea for success, which was solely based on achievement gap and providing support services to increase student retention in a way that the white institution sees fit. When I brought up the racial and cultural implications of MOB in affirming Black urban student lived experiences, she dismissed it and said, "you need another name." I analyzed her as really meaning "you need a different approach that is not about race/culture, and more about college retention." This moment was critical to the foundation of MOB as I was left with a decision to either compromise my ideology for the sake of making it fit in the institution. Or, to roll with the knowledge construction of the community and students; which represented the masses. I chose the masses.

The idea of MOB had already been introduced to Black male EOP students prior to my rejection meeting with the EOP Director. I recall one student saying, "yea I know niggas will hella relate to MOB...that's fire." Furthermore, many of the men EOP students thought that the MOB name sounded dope and resonated with the meaning of My Other Brother. Due to the EOP Directors lack of support, along with my increasingly bad relationship with her, I made the decision to start MOB as a student club on campus to give me full ownership over the program outside of the EOP department. This is important because this decision was a decision that allowed me to create a program based 
on the needs of Black male students, defined by the Black male students. Once again, I would come to learn that the needs of the Black males were highly connected to their Blackness and experiences with discrimination that they encountered. In fall 2015 quarter, I continued to Meet with Black male students in my office to discuss starting MOB and simply being available to support them with whatever they needed. This was the beginning process of seeing the four stages/concepts be developed based on what students would express to me.

One Black male EOP student (who would become a leader within MOB) scheduled a 30-minute meeting with me to discuss graduate school and to ask me about my experiences in grad school. This meeting would turn into a one hour and 30-minute meeting discussing an experience of police discrimination that he experienced over the weekend while driving; he was traumatized, yet very angry also because of this matter. The student stated "this was one of the first times I ever felt like I was treated like I'm not human or something. I was pulled over for no reason, and they made me get out of my car and they made me sit on the curve while they searched my car. I felt humiliated." He went on to explain "I called my girlfriend and left her on speaker just in case something happened. The officer had his hand on his gun as he approached my car. I almost did not even make it back alive."

It is important to point out that our meeting in 2015 was also during the times of the Mike Brown shooting, on the heels of the Trayvon martin shooting and many other police killings of unarmed Black men that was broadcasted daily on media outlets. I asked this student if he tapped in with others about what he experienced and what does he and other Black men need as college students right now in the midst of all of these police 
shootings that we are seeing? Student responded, "I need people like you and spaces like this on campus where I could feel comfortable sharing this type of experience with and who I can be myself with.” In connection to the four Thug Life concepts, this stage of consciousness that this student shared is the following: A recognition of dehumanization/inequality at the individual level as he expressed a personal experience with racism/inequality that he encountered with the police officer over the weekend.

This was also a crash course into this stage for this student, given that he mentioned that this was his first time dealing with police discrimination. Following this encounter with discrimination on an individual level that he experienced with the police, I noticed an increasingly fiery spark in this students' campus leadership/politicization. This student was already a leader on campus in serving as a EOP peer mentor, yet now this student began to branch outside of EOP and get more involved with Black Student Union and campus student leadership task force to get a Black Resource Center established at CSUEB.

In regard to the Black Resource Center, it never got off the ground at CSUEB but other resource centers did. I recall this student expressing frustration over this conveying "CSUEB always puts other groups before the needs of Black students. We should have been started the Black Resource Center; I'm going to keep fighting for it." I was amazed that he invited me to one of the student task force meetings to support him and see him in action fighting for the Black Recourse Center. In the meeting, I witnessed him site his own personal experiences with racial discrimination that he experienced with the police and then talk about all the public police shootings that were happening every day against Black males. These were his arguments in support for why CSUEB needed the Black 
Resource Center on campus to affirm these student experiences. It was such a beautiful scene to watch this student developing his political praxis. And he did so quickly. In the task force meeting, this student brought light to how Black students on campus are impacted by seeing racist police shootings against Black men across America. This was a transition to another important stage within the four Thug Life concepts/consciousness: This was the student's recognition that police discrimination is part of structural racism of which Black people face as a community of oppressed. Moreover, this students hunger to do something, to resist, by trying to uplift his community via him getting involved with the Black Student Union and fighting for the Black Resource Center on campus: Is a stage of recognition of communal/struggle solidarity and a political praxis based on that shared racial alienation. The student became ingrained and politicized to seek justice based on the now many issues that he saw Blacks face as a community.

My interactions with this student helped me understand that connecting this student to a group/community of peers that privileges their shared struggle/inequality to resist alienation is the "resource" that students are looking for within a Black Resource Center. This contrasts with primarily focusing on academics, "tutors," are teaching students" "etiquette" for how to adjust to the college institution and fit in to increase retention rates. In connection to the development of MOB, I recognized a need for MOB to be that "Black Resource Center" that the student was fighting for to affirm Black experiences of alienation. When it came time to have students sign up to be "officers" for the MOB student club (a requirement to be officially recognized as a club on campus), this student of course became one of the original MOB officers. This student along with 
other MOB officers would begin using MOB as that platform to build on those four Thug Life concepts, which would become the four stages of MOB consciousness that we often explored within our MOB work with different activities to hone in on this exploration. Below is another example of how student experiences grounded in the 4 stages of consciousness played integral role in forming the MOB program.

We began having official weekly MOB meetings on campus in Winter 2016 quarter with a group of other CSUEB Black men students that joined. Based on the productivity of our meetings, the CSUEB Vice President for Student Affairs and the Dean of Students invited me over for a meeting to discuss the club. I decided to bring our selected CSUEB MOB Student President (my lieutenant) along with me to this meeting to enhance his leadership in experiencing this meeting with some of the "heavy hitters" on campus. Because there was all of this talk of a need for "men of color" or "Black Male" centered programs to address the "Black male achievement gap" issue in higher education; we came to this meeting pushing for CSUEB to fund our MOB program on campus. This was especially since we averaged 12-17 Black male CSUEB students at our meetings and were already doing some great work on campus like no others were doing for Black males.

The Vice President of Student Affairs pretty much told us that they would not support MOB fiscally but wanted us to continue with the groundwork as a club on campus. Moreover, she pushed for us to allow CSUEB Dean of Students (another Black man who held high rank within the CSUEB institutional leadership) to take over MOB and serve as on campus advisor while I am away in my Doctorate program. 
Also, during this meeting, The Vice President of Student Affairs referenced the EOP Director’s concern for how “MOB sounded like a gang.” My young Lieutenant voiced his passionate perspective at this meeting in addressing the "gang" assertion and the lack of support. He stated "I Feel like there is some coded language that is being used in this meeting that feel like yall are judging us negatively. And you see all of the work we are doing on campus, it sounds like yall want us to keep doing this work but you won't give us any support for it." His discussion during this meeting pointed to his recognition of inequality/discrimination at the individual level in how he felt judged by the Vice President of Student Affairs.

His sharpness in calling out “coded language...I feel like yall judging us..won’t give us any support" demonstrates that he has experienced these forms of inequality before on an individual level. Moreover, he was conscious enough to recognize this as a community of oppressed in naming "us" in his perspective. Furthermore, the lieutenant described this recognition of community of oppressed in his statement "yall want us to keep doing all of the work but will not give us any support/funding." This recognition of a community of oppressed was mentioned in connection to forms of institutional racism in how the institution strives to capitalize off the oppressed Black masses yet take the credit for the oppressed masses work.

I loved my lieutenant's assertiveness and was impressed with his confidence in raising real concerns at this meeting. Of course, the Vice President of Student Affairs was uneasy with the type of energy that we brought to the meeting. To say the least, my young Lieutenant and I both left this meeting pissed off. This experience was another pivotal moment in the foundation of MOB given that we made the ultimate decision to 
seek more community based partnerships (outside of the college campus), which was key in shaping MOB as a community outreach organization more so than a college student club. We wound up following up with the Vice President of Student Affairs and told her that we would focus our work in the larger Black community more so than trying to build student numbers for the institution given that the institution would not support us.

When my lieutenant and I got back to my office to debrief about the meeting. He said "man she was fake and the Dean of Students did not even really back us up like that either." This experience prompted us to reach out to inner-city Black schools for outreach as we began to make our campaign as a real community outreach program instead of just a student club. After conducting an outreach/student panel session at West Oakland Middle school (WOMS); the WOMS principal was so impressed with how our college MOB members engaged with their inner city Black youth that she decided to create a MOU agreement/contract with MOB, of which students would receive paid stipends for conducting weekly outreach to mentor West Oakland Middle School youth.

This experience was critical for two reasons. 1), it was the foundation for MOB as a political praxis: "We do community outreach"-there was now a practical component to MOB that extended beyond a Black male space discussing issues of racial alienation on campus. 2), Most important, student experiences of racial alienation on campus (even along our journey of establishing MOB on campus and dealing with the administrators) would be the spark that influenced us to do community/hood outreach. This gave us our since of independence, and MOB students would now get paid to do the work that they loved in their own way. A way that is not interrupted and not compromised by the institution. 
I would never forget the look of joy/happiness on our MOB lieutenants face when we met with the West Oakland Middle School Principal and confirmed our official partnership. This meeting came on the heels of the lieutenant's successful presentation at WOMS in front of WOMS teachers and staff about MOB and our outreach/mentor approach. After the meeting with WOMS principal, the MOB lieutenant and I shook hands/hugged and he said, "see I told you, all we gotta do is keep Mobbin and do our own thang." What the lieutenant said, and how he said it was like this sense of "we really stuck it to the man and created our own organization our own way." In connection to the four Thug Life concepts discussed throughout this dissertation, "keep mobbin and do our own thang" is a recognition of a political praxis for MOBISM. It was this student's commitment to justice and the understanding that we must fight for what we want. Most important, this "all we gotta do is keep mobbin and do our own thang" is the lieutenant's recognition of solidarity within our communal struggle. This pride and solidarity sparked his commitment to resist the institutional discrimination that we encountered by establishing a program that affirmed our own racialized experiences.

Below, our official partnership established for the 2016-17 academic year with WOMS. MOB members will spend at least 10 hours a week at WOMS and paid for their outreach to $6^{\text {th }}, 7^{\text {th }}$, and $8^{\text {th }}$ grade middle school students with the objective of providing holistic mentoring and instilling systems of high expectations at an early age for students. MOU signed between My Other Brother, West Oakland Middle and CSUEB. MOB Lieutenant lead presenter at WOMS during MOB presentation that solidified our partnership. 


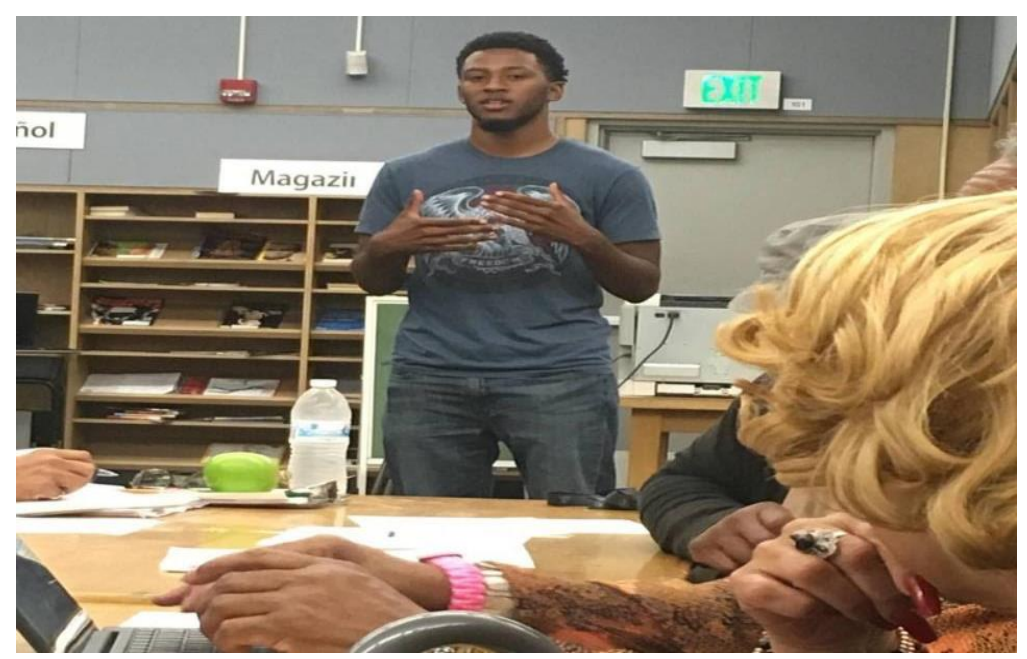

This form of resistance was embedded in a praxis to now mentor and affirm the experiences of inner-city Black youth in the hood in a cultural way that was defined by students. The MOB program privileged this. And similar to the student that I will discuss below, I was excited to see the MOB lieutenant and other MOB members quit their jobs at Target and other campus jobs that students did not like; and now get paid even more money for their MOB work in doing things that they expressed as passionate to them. Students did not have to put on a suit or a collared shirt or compromise their identity in anyway to be hired as MOB mentors for West Oakland Middle School outreach. The only requirement was to keep loving the Black community, keep the passion/work ethic, and keep being themselves grounded in their experiences of racial discrimination/alienation at the community level as a fuel to their political praxis.

Going back to EOP, I witnessed some Black male EOP students that were being themselves grounded in a similar urban Black identity, get persecuted and undermined by the leadership in office as well the campus overall due to their expression of themselves. These students would share these experiences with me in our one on one appointments. Another EOP student that would become an original MOB member (a student that I had 
very close relationship with), was also an Ambassador/Student Assistant within the EOP office. This student would often talk to me about how he gets judged in the EOP office by the office manager. To the office managers credit here, at least she recognized the strong connections I had with students and would often work with me in supporting the Black male students opposed to completely writing students off or snitching on them. But of course, the student internalized his experiences in EOP and CSUEB more critically.

This student would wear urban sweatpants, shorts, $\mathrm{t}$ shirts while working in office (which is actually like how I would dress). He was known for doing very good work. However, The student would discuss with me on how the leadership in the EOP office judged him based on his dress attire and would treat him unfairly in comparison to the other EOP student leaders that were not Black males. In a meeting with me, the student stated, "the other racial groups do not get singled out like I do." In connection with the 4 Thug Life concepts, the student recognized an aspect of inequality that he felt within some of his personal/individual encounters dealing with the leadership within EOP.

In connection to his expression of inequality, this student was actually the first student that I ran the "My Other Brother-MOB" idea to prior to getting it off of the ground a year after my initial conversation with him about it. He would express overwhelming support for the idea of MOB as he would say "man we really need a program like this." I also remember him saying "when we gone get MOB started, because I'm sick of dealing with this shit here." In regard to "the shit" he was referring to, he was talking about working as a student Assistant on campus of which he described as an experience not affirming to his Black identity. In this case, his experiences were connected to the concept of a recognition of inequality/dehumanization at the individual 
level. This experience, as well as the many discussions that we would have in regard to him being a Black man in society in general played a huge role in him pushing me to get MOB off the ground.

It appeared that he was looking for a larger space to home in on the experiences we would often discuss in our meetings. All the way up until winter 2016, I would say this student would ask me "what's an update with getting MOB started" every time I would run into him in the EOP office. It would almost be destiny that he would be the very student that introduced me to our MOB Lieutenant and pushed for him to be the President after we had our very first MOB meeting in Winter 2016. This student, along with the MOB president, and another MOB member that will be discussed later in this chapter: Would serve as the first three original MOB members to serve as Outreach Mentors at West Oakland middle School. Of which we called them MOB "Real Models"instead of role models.

Getting MOB started as a club on campus in January 2016 was the first step to our path to independence in building a Black male space that is by the people and for the people. I would say that we officially became the MOB program, from the community engagement praxis, in May 2016 when we began our community outreach work and solidified our WOMS partnership. In discussion with this student after we solidified our WOMS partnership. He said "I can't wait for us to start working at West Oakland Middle School so then I can finally do what I really love." In connection to the four Thug Life concepts, this student was at a recognition of individual inequality that he experiences as a Black man in his experiences at CSUEB campus. These experiences shaped his eagerness and passion to resist those experiences with a political praxis to serve his own 
community grounded in a space and framework that privileges the very Blackness that he was persecuted for by the larger institution. This student, along with the other MOB members discussed, played a huge role in pushing and affirming my passion to get the MOB program off the ground to affirm students.

By the time we got to Spring 2016 quarter, we shaped a MOB programmatic foundation that emphasized myself and CSUEB Black male students in solidarity having dialogue/building on critical issues that impact the Black community in weekly MOB sessions. I served as the facilitator for these intragroup dialogue sessions and we held discussions surrounding the following themes: Identity development and/or road maps, the meaning of being a Black man, Black men and women relationships and unification, feelings regarding the term 'nigga' and discussions on African heritage, Hip Hop/Black culture and addressing racism and internalized racism. Below are some of our pictures from our MOB sessions captured in real time during the developmental stages of MOB. The thug Life concepts are also captured and contextualized within the below picture narratives that provide further meaning of our developmental stages of MOB.

Winter 2016, one of our beginning MOB sessions on campus that took place in my office. We had a book club discussion on the book "Destruction of Black Civilization," which is a book that discusses the ancient kingdoms and queendoms in early African/Black civilizations and what contributed to the destruction of these civilizations via colonialism. This session featured group chapter readings, followed by a dialogue session on how the reading applies to their lives as Black men in 2016 and the larger community/diaspora. See the below connection to Thug Life and the four concept stages expressed by MOB students captured in the below picture narrative 


\section{$\underline{\text { Recognition of a community of oppressed: }}$}

-Black men together

-Black men arms wrapped around each other, sense of togetherness

\section{Recognition of communal struggle/solidarity:}

-students in close proximity with each other-a sense of "togetherness" in this regard.

-several students in the picture are throwing up the same MOB hand gesture along with me.

-MOB members are all wearing urban Black dress attire via hats, hoodies, geans and sweat pants (and the style of which MOB members are wearing their dress attire) aligning with the dress attire of urban Black community outside of the college institution.

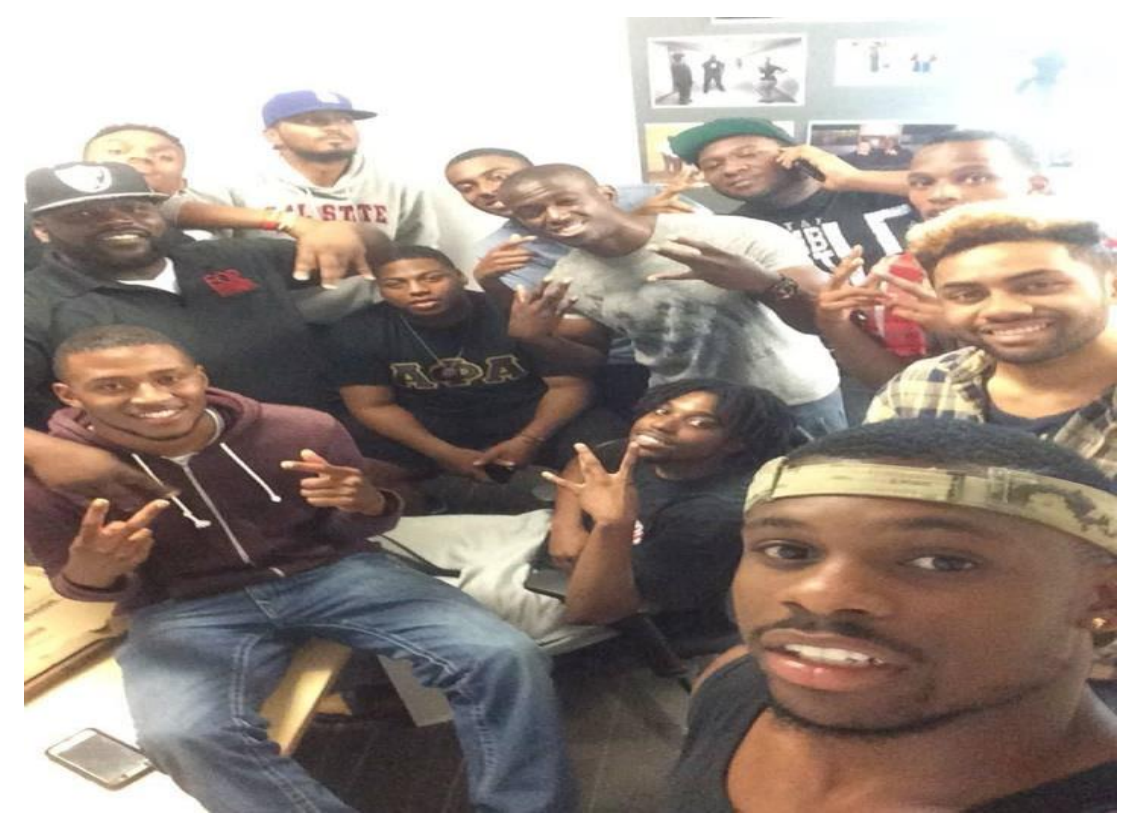

MOB workshop and presentation on CSUEB campus exploring themes of the Black

Panther Party and learning of various laws and policies surrounding gun ownership

rights. Spring 2016 quarter. MOB members invited the larger campus community to this MOB session.

$\underline{\text { Recognition of communal struggle/solidarity: }}$ 
-Three MOB members in this picture are throwing up the Black power/solidarity fist. - Students smiling with each other, displaying a happiness and pride in their communal struggle.

-MOB member throwing up the solidarity fist has on a Black shirt with an image of two Black hands shaking each other's hands. This is also an expression of a recognition communal struggle/solidarity as the locking of Black hands within that image is a call for solidarity-to unify for a cause along a shared struggled of oppressed Blacks.

-Students as a collective also display an authenticity and pride in their struggle-even in how they are dressed in a matter that they want to dress in that is reflected in the picture

political praxis rooted in racial alienation:

-Black power solidarity fist is a symbol of resistance and a commitment to justice. This is reflected in the historical meaning of the solidarity fist, but even depicted in this picture with the sense of pride/manner of which students are throwing their first in the air.

\section{Recognition of community of oppressed:}

All in this picture are posing close to each other, wrapping their arms around each other as a community

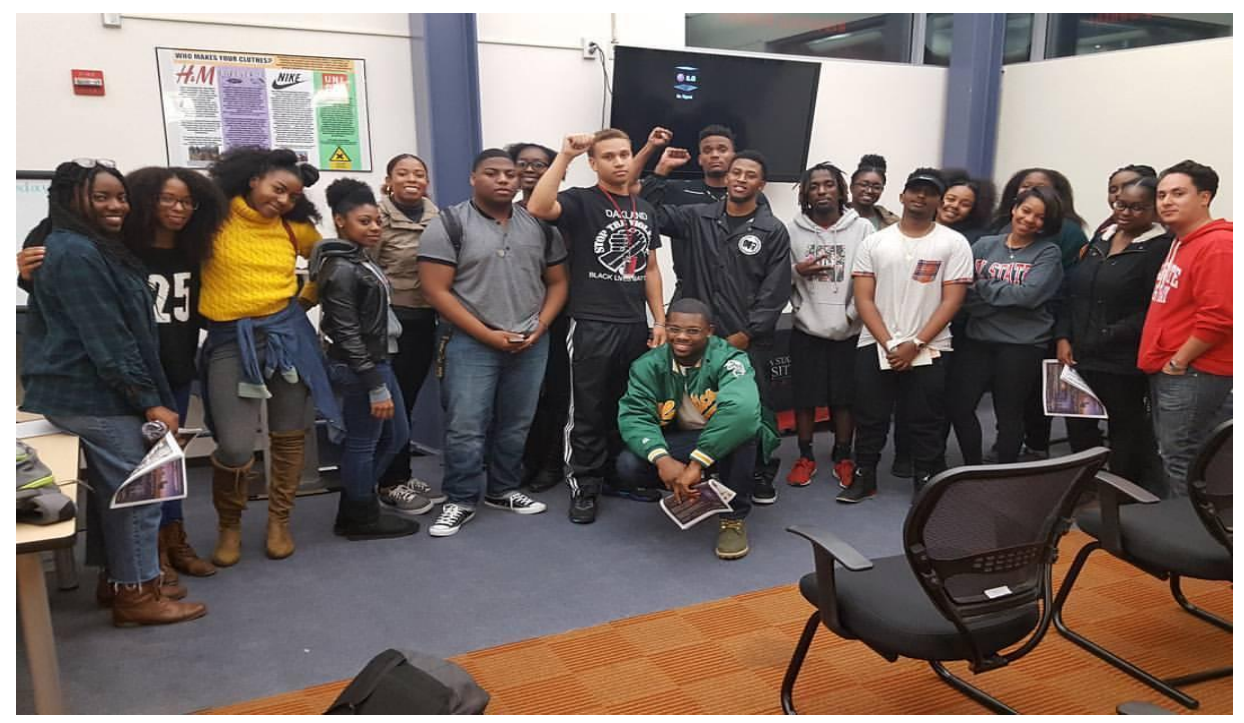

The below picture is from Fall 2016 quarter at CSUEB. MOB session focusing on the Prison Industrial Complex in connection to race.

Recognition of Community of Oppressed:

-Black men and guest in this picture standing together. Students posing together in a similar way, expressing a sense of community.

Recognition of communal struggle/solidarity: 
-MOB members wearing the same MOB hoodie and wearing urban Black dress attire via swaeatpants, geans, Black beanie in solidarity with each other in resisting white cultural norms for dress code.

-MOB members expressing pride in urban black culture and communal struggle, via kneeling in front with a hood cultural pose, throwing up the MOB hand gesture.

-MOB members throwing up the MOB hand gesture displaying solidarity with the organizational purpose/mission

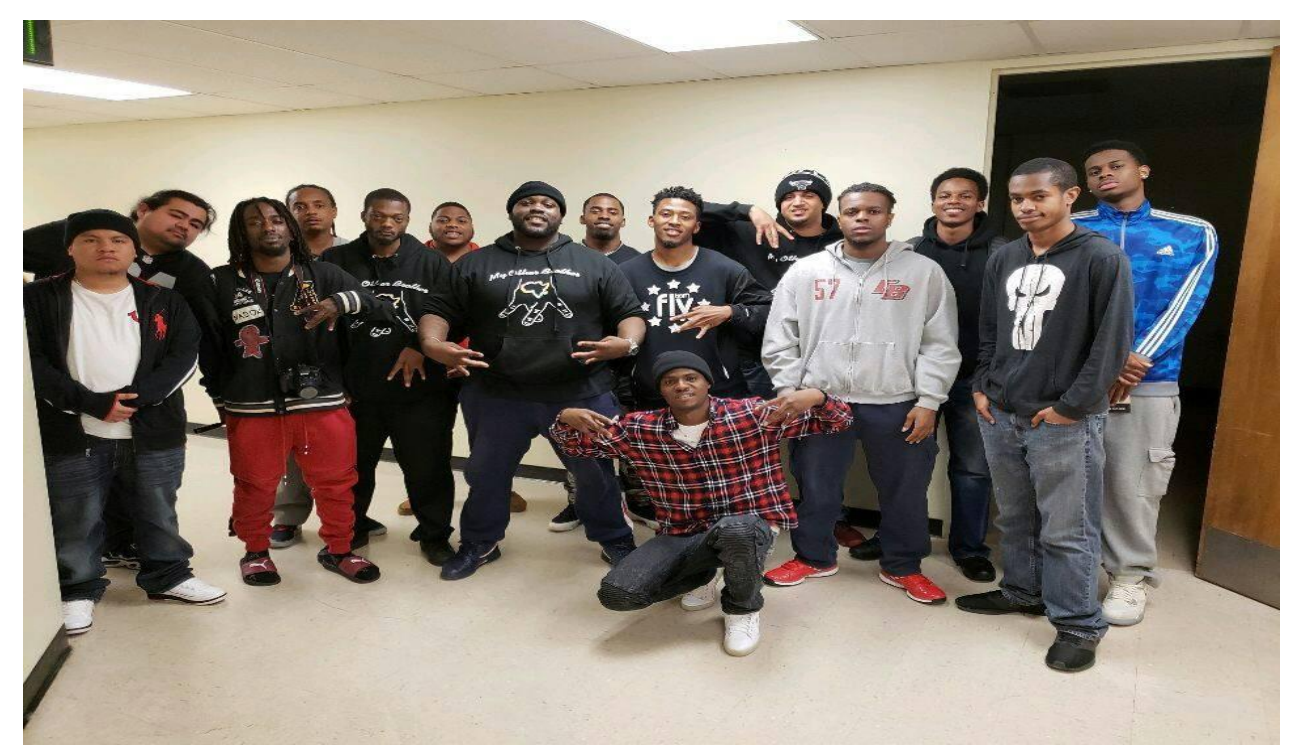

The below picture is from Spring 2016 that emphasizes an intragroup dialogue session. In this session, MOB students expressed their experiences and feelings on the theme: What does it mean to be a Black man? We had a full hour and 30-minute session that was filled with such raw, authentic expression from students. Each student expressed their feelings and thoughts in their own form of expression to the question. Some students utilized poems/spoken word, some used raps, and some students simply spoke/articulated what being a Black man meant to them. After each student shared, we had dialogue surrounding what sparked their expression and feelings that shat they shared in their expression pieces. 
Based on this session, common themes were feelings that African Americans are a threat to society, themes of systematic oppression, feelings that as Black men students feel like they have to be twice as better than their non-black counterparts to "make it" in society. Furthermore, themes that came out were police brutality and MOB students feelings of fear that they can be killed by police for anything at all. Also, feelings of anger toward law enforcement on a systematic level. And themes of both ignorance and empowerment that comes from Hip Hop culture (the good, bad, and the ugly).

Most critically, there were general themes of being tired of being viewed as victims, and a time as Black men to take actions. This is when we started hearing students say things like "fuck the system" in their expression pieces. In alignment with this, students spoke less about what "the white man is doing to us." And instead, students transitioned to speak more about what Blacks are lacking as a race, and solutions like "we gotta start sticking together and shoot back at them." These forms of resistance was also grounded in love, as one student said "and fellas...choose one Black woman, respect her and stick with her." There was a sense of students feeling empowered in that because they face so many issues as Black men and continue to rise above, they feel empowered and feel that nobody else could walk in their shoes. Lastly, the theme of a need for unity amongst Blacks in addition to unity amongst people of color in general. Like the previous MOB picture narratives, below I connect themes from this "what does it mean to be a Black man" session with the four stages of Thug Life as a concept to examine what MOB members expressed in this piece. The below picture narrative highlights what students expressed during this session in real time as what being a Black man meant to them in 
connection to their experiences of racial alienation. This photo serves as field notes taken in real time during this session.

Recognition of Individual racism/dehumanization:

-Slave deal

-Need Fatherhood

Recognition of community of oppressed:

-were getting killed

-Need fatherhood

-commercialism

Recognition of Communal Struggle/Solidarity

-keep others in expense, stop being so predictable

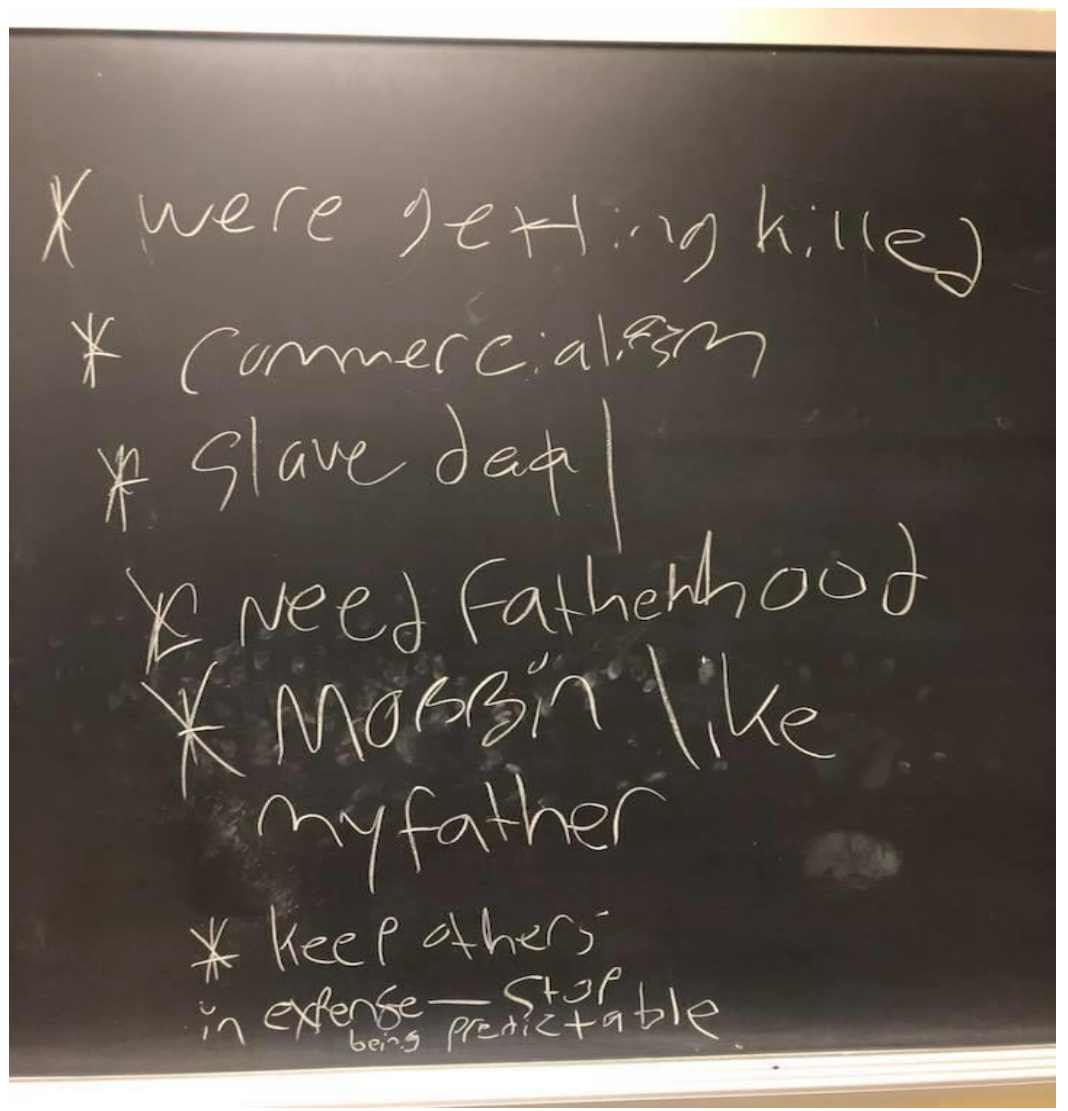

Recognition of inequality/individualized racism and dehumanization:

-Black people hurt me more

-misunderstood

Recognition of community of oppressed:

-system designed for Blacks to hurt each other

-we aint shit

-we Aint about shit

- we havent did shit

-nigga of excuses 
$\underline{\text { Recognition of political praxis rooted in racial alienation: }}$

-empowerment

-fuck the system

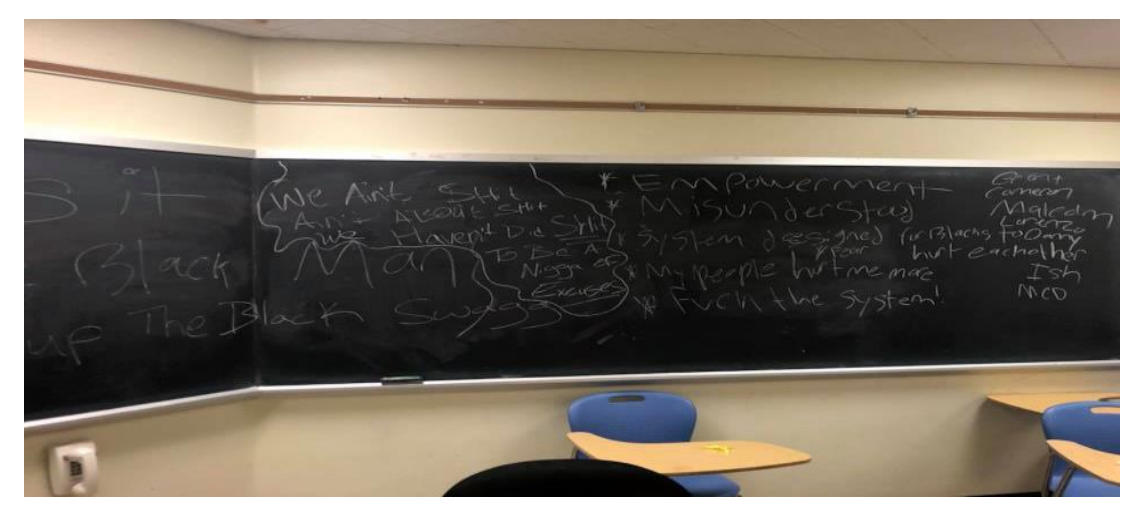

The above campus MOB programming examples within the developmental stages of MOB, reflects a space for students to make sense of their Blackness along those 4 stages of MOB consciousness. This shaped our political praxis for MOBISM- our practical K-12 outreach field work in the community in alignment with the solidarity in communal struggle that we explored on campus as a student club. We established a MOB approach that would use our MOB meetings on campus to discuss Blackness/experiences of discrimination and resistance of discrimination. The "fuck the system" expressed above was praxis for us to take educating our people in our own hands. This sparked a commitment to community outreach as the practical aspect of paying it forward to our community. In alignment, this was the stage of consciousness that recognized at least one aspect of political praxis rooted in racial alienation: Community outreach. A sense of "each one teach one" in feeling a responsibility to be the change that MOB members want to see, in their own way, to impact our youth. The below pictures show MOB members early stages of conducting outreach to the hood Black community. $\underline{\text { Political praxis rooted in racial alienation: MOBISM }}$ 
-solidarity in communal struggle, commitment to justice via community outreach to urban Black youth in West Oakland outside of the college campus: West Oakland Middle School

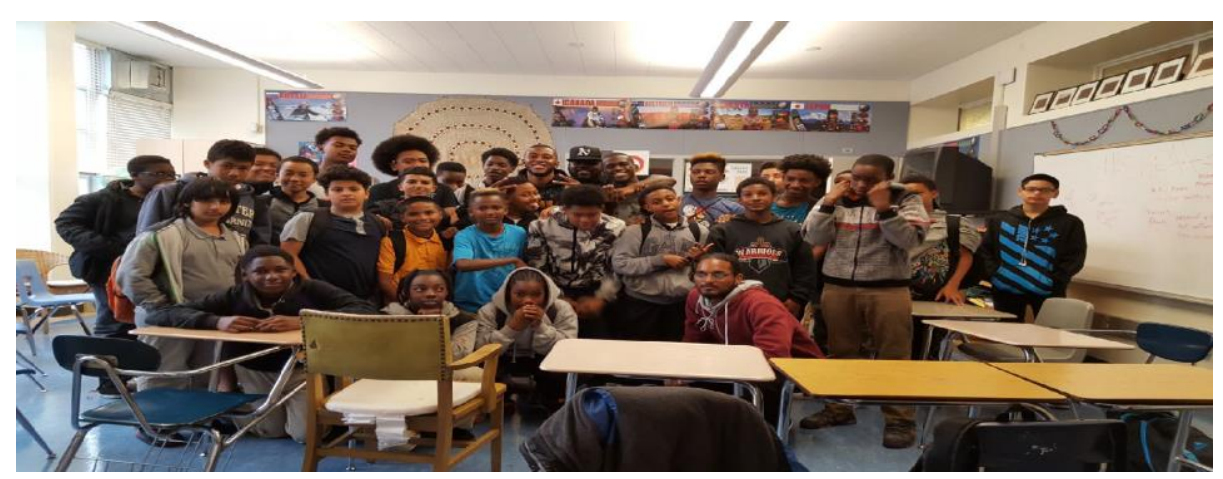

\section{$\underline{\text { Political praxis rooted in racial alienation: MOBISM }}$}

-solidarity in communal struggle, commitment to justice via community outreach to urban Black youth in West Oakland outside of the college campus. West Oakland Middle School. 


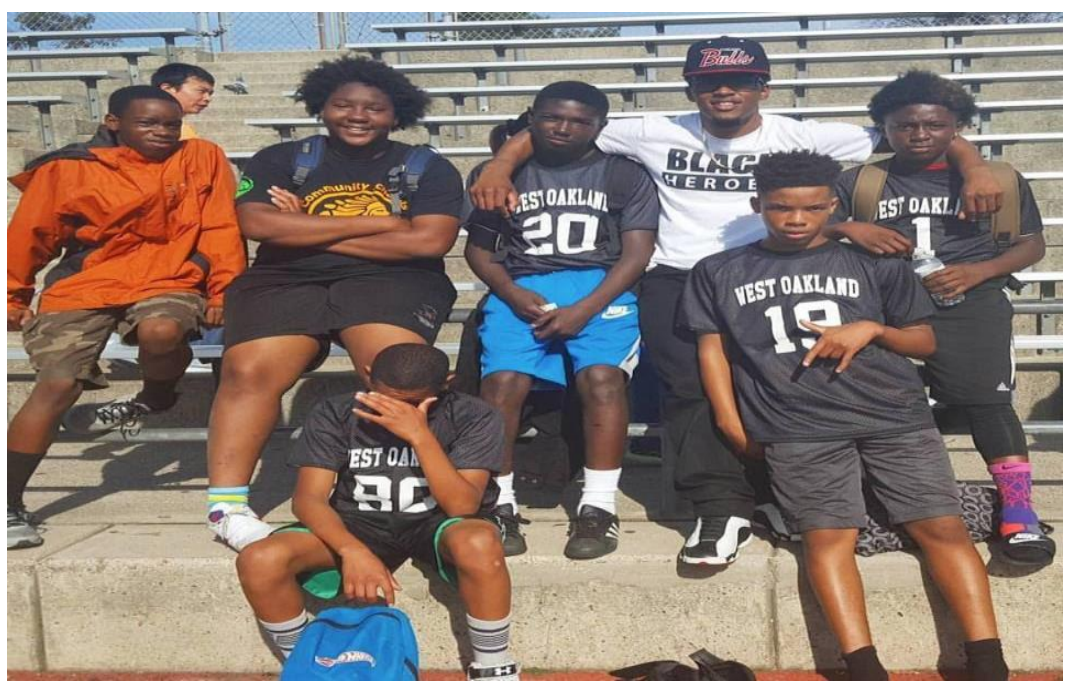

$\underline{\text { Political praxis rooted in racial alienation: MOBISM }}$

-solidarity in communal struggle, commitment to justice via community outreach to urban Black youth in West Oakland outside of the college campus. MOB members working with Mcclymonds High School youth

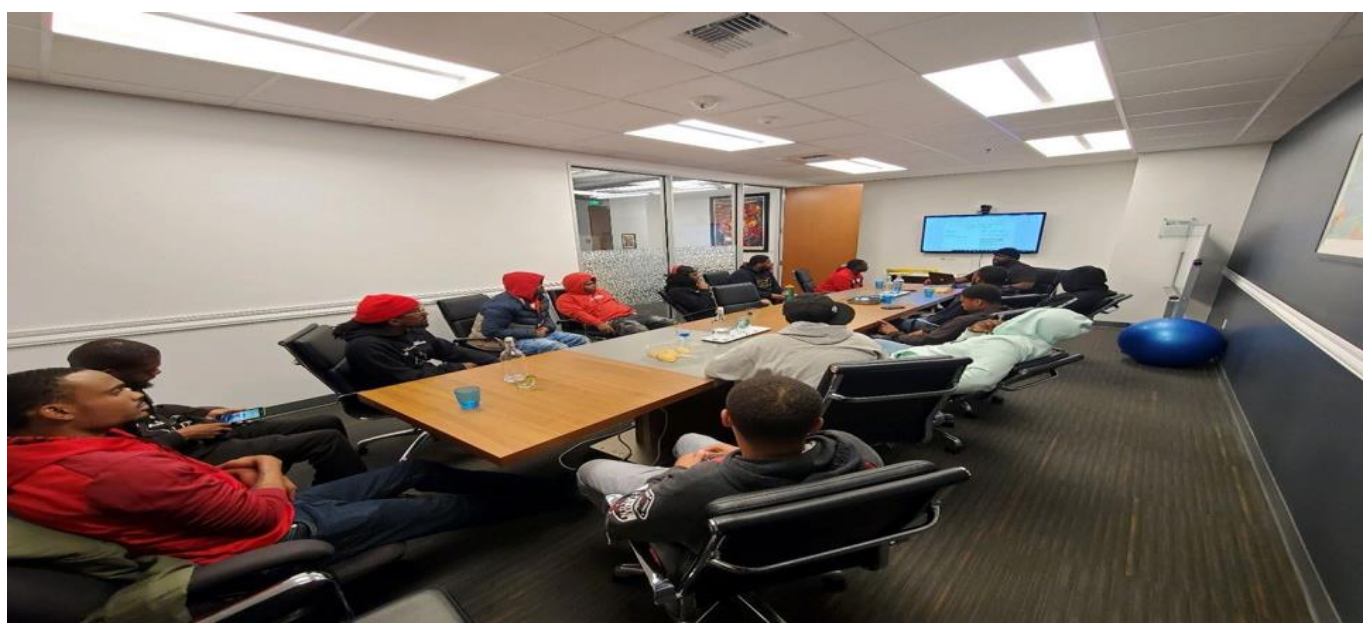


Racial oppression was the deciding factor for the development of the MOB program of which students wanted to do things their own Black way and serve their community. MOB was this Black thing, where students could get paid for doing something that they loved, in their own way without persecution. This was the beauty of being part of the institution as a club, yet still resisting the institution and being able to do our won thing given that our funding came from the community (giving us ownership).

Whereas EOP allowed me to work with Black men and students of color in general on an individual level. MOB was different in that it provided a platform for us to explore our worlds on a deeper level by grounding our experiences with a community of peers that shared common experiences. In Alignment, further data reflected in MOB student findings from this study is a reflection of how they make meaning of their Blackness throughout their experiences in the MOB program in solidarity with the experiences of the oppressed Black masses in the larger world outside of school that impacts them. Moreover, when we analyze MOB student narratives in response to the question: What Does MOB Mean To you? You will see that the data points back to the historical/foundational reasons for why establishing the MOB organization was so critical to both students and I in solidarity.

\section{MOB in Practice}

There are certainly biases in how the above findings/data is analyzed given that I am the director of the very program that is being evaluated and analyzed in this study. In solidarity, these biases are necessary to the over- standing of the importance of telling your own story. Not only telling your story from an individual perspective, but a programmatic perspective given that this story telling aligns with how MOB functions 
practically in connection to MOB student development. This is the power of the auto ethnography featured thus far in this study. Furthermore, the reason why storytelling and self-reflection is a tool for the program evaluation method of this study.

From a practical approach, MOB is a program that politicizes College Black males through culturally/race-based programming to influence MOB students to contribute to the upliftment of themselves and the larger Black community as a praxis for justice. Data from this study reflects that this shows up in the form of 1) students serving as educators in the larger Black community through their MOB work mentoring K-12 youth or other opportunities that they seek in urban education based on their MOB experiences; 2) academic success outcomes such as students graduating from college and taking on opportunities that align with their Black empowerment (example being one MOB student who just graduated and is now an Engineer, while being a Hip Hop artist that pushes themes of racialization and empowerment in his artistry).

The story telling within this study provides deeper context to MOB practices that center on Black male student experiences that shapes justice. In this case, evaluating $\mathrm{MOB}$ as a program is to make meaning of how $\mathrm{MOB}$ members navigate and resist processes of racial discrimination to impact a praxis in solidarity with their racialized experiences as a strength. The below narratives convey what MOB represents to Black male students based on their experiences in the MOB program from a practical approach.

\section{What MOB Means to Black Male Students}

Twelve MOB students responded to the question "what does MOB mean to you," to examine how Black males make meaning of their experiences in the MOB program. 
MOB members expressed that the MOB program affirmed their racialized experiences (day to day experiences as Black men in society dealing with racism), provided students with a sense of community/solidarity grounded in their Blackness, and furthermore enhanced students authenticity and pride in their Blackness which fostered a justice oriented practice to uplift the larger Black community outside of the college campus. What is most important when diving deeper into MOB member experiences is that their meaning making systems for these salient concepts are tied to their experiences with racial alienation in the larger society.

Everything is connected to the larger struggle within the oppressed Black masses. For example, one MOB member mentioned that the MOB program "impacted me in a way that it helped me to connect with other people of my same demographic and similar lifestyles in a way that I wouldn't have been ever if I were to try to make connections on my own." Of course, MOB students and I initially coded this under the concept of "sense of community/solidarity." Yet, when centering this concept within the larger context of racial alienation on a systematic level: The MOB member is recognizing his positionality within a structure of domination/racial hierarchy dehumanization at the community level. In other words, this is a recognition that being put "with other people from the same demographic with similar lifestyles" through his MOB experiences is a recognition that he is a member of a community of the oppressed; and not alone in his struggle/racialized life style. In connection, the below data analysis dives deeper into what students are saying and further contextualizes the themes of Blackness/racialized experience, authenticity/racial pride, community/solidarity, and justice. 
There is a deeper stage of consciousness that is behind the concepts found in the twelve MOB narratives. The below analysis further illuminates this within four stages of MOB consciousness grounded in the four Thug Life concepts. Out of the twelve student narrative responses, below I use three critical MOB narrative responses to illuminate the impact that MOB had on students. The four Thug Life concepts reflect the stages of MOB consciousness expressed by students within the below narratives.

\section{MOB Narratives and Thug Life Concepts}

1.) $\mathrm{MOB}$ means family, $\mathrm{MOB}$ means Black men together, learning from each other and teaching youth and yeah, that's what MOB means to me.-(MOB Member narrative)

In this above narrative, this $\mathrm{MOB}$ member explained that MOB represented family in the sense of "Black men coming together." In placing this narrative in proper context within my personal discussions with this student, Black men coming together, and the sense of family is a necessity in affirming this students' day to day reality as a Black man. In connection to the Thug Life concepts, "Black men come together" is a recognition of a community of the oppressed. In this stage, this MOB member makes clear recognition for a sense of community via a space where Black men come together. Within this same narrative, the student points to the impact of being within a community of individuals that share a similar struggle. Moreover, within this same narrative, there was a transition to another stage of consciousness of which this student recognized a sense of solidarity with his Black male peers to reach a common goal.

In the recognition of communal struggle/solidarity stage within the four Thug Life concepts, students begin to identify the need to educate themselves to resist the racism that they face as a collective/community. This MOB member expressed this by 
conveying "learn from each other." In this case, this student expressed MOB as not just a space where Black men come together (community of oppressed), but it is a space where Black men come together and learn from each other (communal solidarity). In working with this student for three years within the MOB program, the "learning from each other" is grounded in MOB members discussions of historical, systematic and individual level discrimination and various solutions to addressing these problems as defined by the Black male MOB members. This connects to the final stage within the four Thug Life concepts in alignment with MOB: A praxis to do something about the collective struggles that MOB students experience and highlight in their work.

For this MOB member, his political praxis rooted in his experiences with racial alienation was to "teach youth." Within this short narrative, this student is expressing that MOB represents a sense of family where Black men come together, learn from each other, thus impacting his political praxis to pay it forward by teaching youth. In connection, this data points to how MOB Members flow through different stages of consciousness throughout their narratives. And most critically, students have different meaning making systems for what their political praxis is.

What you will see that is consistent across all narratives is: 1) MOB members political praxis was grounded in their collective experiences with racial discrimination; 2) students have various types of discrimination that they experience, subsequently how they choose resist discrimination varies from student to student; 3) The justice/political praxis, across the board, was a form of resistance that was defined and implemented by the students collectively, grounded in a sense of them taking matters into their own hands in contrast to appealing to the racist institution for justice. Justice was grounded in a 
commitment that students have in being the change that they want to see. In this MOB members case, his commitment to "teaching youth" himself is an act of resistance/justice as he feels that he can impact his people better than the "system" can. In this case, it is his responsibility, as a Black man, to teach his Black youth. These various Thug Life stages of consciousness were also expressed as a continuum in the below narrative.

2.) Hi, my name is Jonathan Amey, I'm a fifth year graduating senior. I major in multimedia and I've been in MOB since it started. What does MOB mean to me? It means community. It means family, it means a bond we build with people who looks just like you. Be able to come to them and express some issues that we go through as being black males and how do we counter those situations. Make our community better, and not only that but also how to appeal to the younger people in the middle schools and high schools to help them learn how they can build their own community and how they can continue to stay strong and be leaders in the future, do all they can to continue to build our black community and take over the stereotypes that is put upon us as black males. Also MOB means to stand strong, continue to show leadership, being all about the community and take away the negatives that are all about us.-(MOB Member Narrative).

Similar to the first narrative, this MOB member expressed that MOB meant "community and family"-of which I categorized this within a recognition of community of oppressed. Furthermore, this theme was followed by the Thug Life concept of communal struggle/solidarity. "It means a bond we build with people who looks just like you." This line from this narrative was more so an expression of communal struggle/solidarity given that the student mentioned the word "build" and "bond"- - which 
expresses some sort of shared goals to build on along students racialized struggles. Yet, "issues that we go through as Black males" was a jump back to the stage of consciousness that points to his recognition that he is among a community of peers that shares the same oppression/struggle. And once again, this was followed by "and how to counter those situations"- which is a recognition that the issues that they face as a community of Black men must prompt a sense of solidarity in finding solutions to this issue. This data further demonstrates that $\mathrm{MOB}$ members navigate these different stages as a continuum within their MOB experiences. Yet, sometimes these stages are also linear.

Data reflects that MOB members building solidarity within their communal struggle in most cases was always followed by the political praxis to do something about it; which is justice, MOBISM. In this MOB members case, the "issues that they go through as Black males (recognition of community of oppressed) and finding ways as a collective community to "counter those situations" (recognition of communal struggle/solidarity) is an example of how the Thug Life concepts can flow in a linear way at times in regards to student experiences with racism and development of resistance. The communal struggle/solidarity stage reflected when this student discussed "countering the issues that they go through as Black males" shaped the following political praxis for this MOB member: To "Make our community better...appeal to the younger people in the middle schools and high schools to help them learn how they can build their own community and how they can continue to stay strong and be leaders in the future." Furthermore, "continue to build our Black community and take over the stereotypes that is put upon us as Black males." 
This data reflects that MOB members political praxis is his commitment to engaging the youth of the Black community and pushing them to build their own communities. Like the first narrative, this MOB members political praxis for success was grounded in the need to teach and work with youth. To teach and work with Black youth to "build our own community." This speaks to MOB members meaning making systems of resistance in alignment with knowledge that is by the Black community and for the Black community. This is a resistance that privileges MOB members ideas for what justice/success looks like based on their experiences with racial alienation.

Critically, This MOB members political praxis was also a call for his fellow Brothers to "be leaders" and "take over the stereotypes that they put on us as Black males." Taking over stereotypes that they put on us as Black males is a praxis to resist the institution that creates anti Black stereotypes, of which this MOB member will "take over," by constructing his own image that is affirming to Black males. Again, this is most important to the understanding that student's political praxis for justice is by means of taking matters into their own hands by being the change that they want to see. These themes carry over to the below MOB members narrative and how he constructed his political praxis based on his experiences in the MOB program.

3.) What MOB mean to me is growth. Growth through myself meaning that I recognize what authentic culture mean to me and what authentic leadership mean and how to portray that at East Bay. MOB help me explore my identity as a black male and also from the culture I stand from. So with moving forward I will assert myself in all spaces whether be work, school, society and life in general in a whole different mentality. 
Because I believe in the collectiveness and that's what MOB means to me as well. Cause its moving as a collective meaning. We mobbing together, we stretching, we got rules. We just moving and just doing everything in a positive way. And to make sure that our society, our community is structured in that way as well as a MOB. MOB meaning no matter what space a black person is in they will be supported. -(MOB Member Narrative)

In the political praxis rooted in racial alienation stage within the Thug Life concepts, students begin to engage in political praxis rooted in their sense of pride in being Black. Students have recognized their shared experiences with racism, have expressed a collective affirmation in their Blackness and have made a commitment to resist the structures that they have identified. In connection, the above MOB members narrative reflected two core aspects for his political praxis: 1) A dedication to pushing positive outcomes for his Black community and making sure that every Black person in society is supported in all spaces that they are in; 2) on an individual level, asserting himself in all spaces whether it be work, school, society or life in general. This is what success, justice, and resistance against racial discrimination looks like to this student as a function of his political praxis.

In alignment with the previous two MOB member narratives, this political praxis is grounded in Strictly for my N.I.G.G.A.Z. This MOB member expressing that he must assert himself in all spaces, support all Black people in all spaces and push a sense of structure/MOBISM in the Black community to impact positive outcomes for the community: is grounded in the idea that Blacks must liberate themselves in their own way-grounded in solidarity with his oppressed Black community to uplift the Black community. Moreover, data from this narrative reflects students' individual experiences 
resisting discrimination regarding the institution framing his Black culture and identity in a deficit lens.

This MOB member developed a recognition for a communal struggle/solidarity to resist this racial alienation by recognizing "growth through myself meaning that I recognize what authentic culture mean to me and what authentic leadership mean." He went on to say "MOB help me explore my identity as a Black male and also from the culture I stand from." This is an aspect of student gaining a sense of pride in his Blackness, thus recognizing this culture as a strength in impacting his political praxis. It was his newfound pride in his Black male identity and culture that shaped his confidence to assert himself more in all spaces. Moreover, this shaped his political praxis for his commitment to uplifting his community and striving to support all Black people.

This is a critical point in the data given that it speaks to how Black male students simply being themselves,-in alignment with their culture and identity, is a form of resistance against white cultural norms and values as a function of Black male success. The concept of resisting politics of respectability via privileging "the culture that the Black male stands from" as this MOB member stated, is in alignment with the Thug Life theme consistent in all of MOB members narrative. Which is an idea of success that is grounded in solidarity with meaning making systems of those students and communitiesopposed to the institution. Below are the most salient concepts found in MOB member narratives.

Most Salient MOB Concepts

- Recognition of inequality/individualized racism-dehumanization (racialized experiences/Blackness) 
- Recognition of community of the oppressed (sense of community)

- Recognition of communal struggle/solidarity (authenticity/racial pride)

- Political praxis rooted in racial alienation- MOBISM (commitment to justice and resistance via uplifting the Black Community on an individual and systematic level)

\section{Data Analysis:}

In connection with the above MOB member narratives, this study suggests that there are four key stages of development along the path to MOBISM. This path is an arduous one, in which students have critically reflected on their experiences with racial alienation. Through this reflection, they developed mechanisms to challenge these forces both individually and collectively. MOB has played a crucial role in this development. Below, I provide a detailed discussion of each of these crucial stages in order to provide insight into the philosophy and praxis of MOB and to further contextualize the above themes/concepts found in the above MOB narratives. My aim here is to draw attention to the interventions developed, and the ways in which they are necessarily individualized and collective. In this way, MOB is a program that is constituted by a collective consciousness and praxis.

They don't give a fuck about us

Racialized Experience/Blackness:_Recognition of Inequality/Individualized RacismDehumanization) 
One theme that emerged from the data was student recognition of racism in connection to how they experience their Blackness in their day to day interactions. Several MOB members expressed frustration over feelings that they frequently subjected to racial discrimination on campus and in the world outside of campus. For example, one MOB member from this study expressed his feelings on what it meant to be a Black man. MOB member Cameron stated "Being a Black man, I feel like I gotta worry more about the police than worry about gang members and stuff. I gotta make sure I am not wearing a hoody at night." Cameron grew up in South Central, a first-generation college student and had been in the MOB program since the very first day we started in 2016.

Cameron was also an EOP student who I had developed a close connection with since his freshmen year at CSUEB. What Cameron expressed in this discussion piece regarding his encounters with the police are aspects that we would discuss often in our one on one meetings in addition to our MOB meetings that gave space to express his racialized experiences. What is critical to point out here is that Cameron, like many of the MOB members, could not separate their racialized experiences in the larger community, as a collective, from their meaning making systems as college students on campus. Cameron expressed his experiences with his Blackness intertwined with on campus and outside of campus experiences. The experiences of discrimination expressed by Cameron clearly impacted his experience on campus given that he expressed this narrative in our CSUEB campus classroom of which we had our mob meetings at.

Cameron went on to say "Specifically, when I was at home during Thanksgiving break, I left my keys in the house and I was locked out. And my phone was left in my friend's car. Right now I live in Compton, I was walking down the street to get to 
McDonalds. Walking past King Drew High School. I had my hoodie on and police stopped me immediately. Saying, like where are you going and you look suspicious and stuff. And all I had in my backpack was my macbook so that I could text my sister. All I needed to do was get some internet service at Mcdonalds. But he assumed that something was going on, I shouldn't have been walking around at 12:30 at night or whatever time it was. I realized I was on a dark street alone, I just asked could we continue this conversation on a more lit/bright street because it was not going to go the right way. So basically we got over there towards Wilmington and 120th street, and he immediately said you still look suspicious I need to go through your back pack. There was a little bit of arguing going on between us now because I know my rights. It was just people standing next to me and they saw what he was doing,-he was like harassing me. I felt that if I would have stayed in the dark area, something bad would have happened to me. So I am just happy to see another day."

Cameron's experience of discrimination by the police officers mentioned in his narrative is just one example of how Cameron made meaning of his individualized experience of racism/inequality. Most critically, it was an experience that connects to the Tupac heading above, “They Don't Give A Fuck About Us.” They Don't Give A Fuck About Us is the name of a Tupac rap song that emphasized experiences of Blackness in regard to police brutality and other forms of discrimination that Blacks encounter on a day to day basis. In Cameron's narrative, he is expressing and shaping his own political understanding, -at the basic individual level, that "They Don't Give A Fuck About Us." The "they," as it pertains to Cameron's narrative, is the racist police and other folks that have discriminated against Cameron. This recognition of racial discrimination, a 
recognition that “They Don't Give A Fuck About Us," would be a common theme expressed by other MOB members as well.

Jonathan Amey is another original MOB member that started with us in 2016. Jonathan is from the hood' in East Oakland and a first-generation college student at CSUEB also that I met through the EOP program first. When giving him a platform to express what being a black man meant to him in our very first MOB session in 2016: He responded "I think personally being a Black man even in America, you gone have constant battles, there is no such thing as rest, there is no such thing as getting water (in a figurative sense). You always gotta keep fighting you know that these cops are going to keep coming at you constantly. Sometimes you gotta try not to act up sometimes, they gone find any and every excuse to just pull out a gun and blast you right then and there. I have been harassed plenty of times where I was walking down the street with my headphones. I didn't know the police was right there. Until he had to come out of the car and wave at me to go check me or whatever. My headphones and stuff dropped and I didn't pick them up right away because I didn't' want them to think I was going to try to pick them up and run,-he probably would have shot me so,-I went down kind of slowly to pick them up. They put me in the back seat and asked me where I was coming from? I said my friend's house. They said are you serious? I said yea and they gone ask me that same questions like two more times. I gave them the same answer.” Like Cameron's response, experiences of racial discrimination (something that took place in the masses/urban community of which he is still part of outside of the college campus) impacted him as a student overall. 
Cameron talked about his experience back home in South Central/Compton. Jonathan talked about his experience with the police back home in Oakland. This conveys that the concept of "They don't give a fuck about us" in both Cameron's and Jonathan's narrative is not just their expression of discrimination and racism/dehumanization on an individual level. But it is also an expression that the racialized encounters that they experienced, is a thing that many Black men (whether one is on college or not) go through especially in the inner-city hood' Black community. In this case, Cameron and Jonathan's meaning making systems were discussed in alignment with the community of oppressed Blacks within the larger inner-city communities. The experiences of racism (police oppression in this case) that are prevalent in the larger urban black community: Were still part of the realities of Cameron and Jonathan, even though they were in college.

Similarly, LD Larkins (another original MOB member) first generation college student from Southern California, expressed that "being a Black man in America means I have to look over my back. Being a Black man in America means that my actions are amplified. Being a Black man in America means that I already have a hill to climb. Being a black man in America means they don't want me to succeed." In connection to what LD said, first generation college CSUEB MOB member (who joined the MOB program in 2016 as a community college transfer student)-Kimane Juneau, stated "It reminds me when I was a little boy, my grandmother used to tell me you are a Black man in America. She was telling me I have two times the struggles in life." Kimane, Cameron, LD and Jonathan are all similar in this case in their expression of "They Don't Give a Fuck About Us" in their recognition of the inequality/racism that they have experienced on the 
individual level. This processing also lead to a recognition, a positionality in MOB members over standing that their experiences of discrimination at the individual level, are part of a community of the oppressed of which other Black folks face similar experiences of discrimination.

\section{I guess it's cause we Black that we targets}

Sense of Community: (Recognition of Community of the Oppressed)

Another theme that emerged from the data was student recognition that racism and how MOB members experienced their Blackness on an individual level, is in alignment with a collective community struggle of the oppressed Black masses. In other words, the discrimination that they face is not just on an individual level in their experiences at the college level, but it is structural, systematic and impacts the Black community overall. Several MOB members in this study expressed that the MOB program provided them with a sense of community, brotherhood/family with their Black peers in the MOB program. In connection to this piece, this sense of community was grounded in the over standing that they were part of common struggle that they all faced as a community of Black men (Black people in general) within a structure of domination. One student, Khalil Corbin expressed this theme in many of his views within the MOB program and one on one meetings with Khalil.

Khalil mentioned "Nothing has changed since Emmit Till. Public lynchings happening all around. Trayvon Martin, Mike Brown, Eric Garner, three major examples of today's lynchings. The Boys in blue are the modern day Klan! Young brothas scared to drive and stay too late. Pull up next to me in traffic, can't look the officer in his face. Prolly try to give me 5-10 after running these plates. Po-po quick to spray at us, using 
bullets like mase. Seems like Police are being called as exterminators. To get rid of all the pest. Pull out the pesticides and spray at the "unwanted guest." In this piece, Khalil is conveying exactly what Tupac expressed in the above title, "I guess its cause we black that we targets." This title is how Tupac expressed how Black male experiences with discrimination is connected to a larger structural hierarchy of dehumanization. Most important, the "we," in I guess its cause we Black that we targets: Is most important as a concept to expressing how this problem of racism is a thing that Black folks experience by the masses as a community, not just on an individual level. Khalil expressed this "we" in saying "young brothas scared to drive and stay out too late." He connected this to Emmit Till, Eric garner, Trayvon Martin, Mike Brown and other Black men experiences as a collective with police brutality. Another MOB Member, Cameron Turner (first generation CSUEB college student from the hood of Pittsburgh Ca), conveyed this meaning in connection to what Khalil said on a more systematic/structural level.

Cameron Turner stated, "If you peep game, the system that was designed years ago is designed for you to not only fail, but for you to gain a certain perspective. I Said, if you peep game, the system that was designed years ago is designed for you to not only fail, but for you to gain a certain perspective. The system is a problem, and it is designed for a white person to think and act in a certain way. So you don't think it's designed for us to think and act in a certain way?" Cameron is talking to the masses when he says "so you don't think it's designed for us to think and act in a certain way." In this respect, like Khalil and MOB members in general, Cameron is expressing a political ideology that places Blackness and structural inequality at the forefront of his meaning making systems that impacts Blacks on the community level. Furthermore, it is important to point out that 
the slain Black men that he mentioned (tryavon, Mike Brown, Emmitt Till), are a product of racialized experiences amongst the low income, working class Black community. As such, the urban Black masses in connection to experiences of racism at the individual level and community level are grounded in the themes that MOB members are constructing here. Moreover, a sense of pride, love and community along these racialized experiences that students expressed, have built a sense of pride and resiliency to resist this structural discrimination.

Data from MOB study findings reflect a recognition of communal struggle/solidarity around experiences of alienation and structural inequality that MOB members expressed in their narratives to impact their success. This established pride and authenticity around this common struggle that sparked the developmental stages for MOB members wanting to do something about the structural inequality that they experience as a community. In this case, students meaning making systems for "success" did not appear to be what you would expect from college student leaders on a college campus. Their framing for solutions to their experiences as Black males with racism were grounded in the larger struggle of the Black community to impact individual and structural justice in some context. A recognition that MOB members are amongst a community of folks that experience the same struggle, provided a positionality and a sense of pride in their Black identities within this struggle to counter racism. Who you are, is what you do. As such, I defined students' identities in connection to their racialized Blackness given that their aspirations and practice to make change were grounded in this experience.

\section{Conquer the enemy armed with education}


Authenticity/Racial Pride: (Recognition of Communal Struggle/Solidarity)

Another theme that emerged from the data was student recognition that systematic anti Blackness (structural discrimination/inequality) that they experienced as a community, established a sense of pride/resistance. MOB members expressed solidarity in a collective expression of Blackness as a consciousness to empower themselves. This is the foundational piece that shapes the praxis of MOBISM: The actions, the justice, the practical approaches to students living out their Black empowerment grounded in what the urban Black masses deem as a form of justice against structural oppression. Several students expressed that a sense of community, brotherhood/family built through the MOB program shaped a sense of pride and resiliency in students collective Black struggles to impact their success. This pride and resiliency is the beginning praxis for students searching for solutions to address the problem of anti- Blackness in the world.

For example, Cameron Martin expressed "being a Black man in America, You get knocked down but you gotta keep getting back up. Keep pushing, marching forward, don't let the little battles stop you. Because that's what they want to do, they want to stop you. They know how strong and intelligent the Black man is. They see how powerful it is when they know how important it is to get the knowledge and go to college." In this example, Cameron's pride and aspirations are grounded in his community of oppression and the subsequent resilience/resistance that is birthed out of this membership within the community of Black oppression. "You get knocked down... you gotta keep getting back up...they know how intelligent the Black man is.....they see how powerful it is when they know how important it is to get the knowledge and go to college." This sense of 
"fighting back," "getting back up," and "getting the knowledge and get to college" expressed by Cameron is critical.

This is important because MOB members expressed this grounded in the meaning making systems of the Black masses. Because their experiences are not just isolated as Black males in college,-rather, they are connected to the larger community struggles that we have discussed thus far with systematic issues and police brutality. In this case, MOB members shined in our MOB platform in expressing their political praxis for success that is embedded in their lived experiences as Black men as a whole. "keep getting back up" is a theme that Cameron has discussed with me many times in relation to how he deals with issues at the college campus, academics, encounters with instructors, as well as issues in his experiences in the larger community outside of college. The MOB lieutenant is a former inmate that had to fight off a felony case that landed him in jail prior to his college journey: He is a community college transfer student from the Double Rock/Hunters Point neighborhood in San Francisco: Most critically, an original MOB member, first generation CSUEB student who held the rank as the MOB lieutenant (MOB President from 2016-2019). Christian connected this sense of solidarity/empowerment within community struggle in connection to how Tupac conveyed "Conquer The Enemy Armed With Education."

Tupac, similar to what Christian expresses in regards to "Conquer The Enemy Armed With Education," is a foundation for a political praxis of racial pride and success based on empowerment that is grounded in,-and response to,- the structural dehumanization that Blacks face collectively. Christian expressed that "Being a black man means being victorious. I know we have been through hell before. Knowing that our 
people have been through so much and have overcome so much, that we can push it even further. We can Recognize our excellence and go even further." Connecting back to Tupac's "Conquer The Enemy armed With Education," some of the lyrics from this same rap song state "armed with knowledge of the place we've been, no one will ever oppress this race again." The knowledge that Tupac is conveying is the education and knowledge of self.

It is the education and knowledge of a Black collective and historical struggles that bond the Black community together, using the struggle as a sense of empowerment. In Christian's case, "knowing that we have been through hell before...our people have been through so much," is what shaped his praxis for "being victorious" and "recognizing our excellence to go even further;" this is the empowerment piece. The community solidarity grounded in collective/historical Black struggle expressed by Christian and Cameron to impact success/justice shapes a political praxis rooted in their racial alienation: MOBISM

\section{N.I.G.G.A: Never Ignorant Getting Goals Accomplished}

Justice/Success: (Political praxis rooted in racial alienation: MOBISM)

Another theme that emerged from the data was a recognition that the systematic anti Blackness (structural discrimination/inequality) that students encounter built a sense of community and solidarity amongst students. Most critical, this solidarity influenced a political praxis for success and justice by MOB members own definitions. This success was expressed on an individual level. For example, MOB members succeeding in life and in their educational outcomes and not allowing oppressive forces stand in their way. On a community level, MOB members defined success as taking up roles of leadership in 
engaging and empowering the Black community to resist systematic oppression and empower youth and the community overall. MOBISM is the politicization of Black male MOB students in their awareness and dedication to systematic resistance against systematic oppression in however this shows up for MOB members.

For example, on a systematic level, Cameron Turner conveyed that "When you introduce the truth to the system, the system will be no more, and the system will have to go and create something new. Forget trying to put patches on something that does not need patches because it was designed to work exactly how it is working." Cameron is expressing the need to be part of the building blocks of a new system that is for the Black community and by the Black community. This is important because it is grounded in his realization that the system that produces structural inequality amongst Black men "was designed to work exactly how it is working." As such, the system must be dismantled with a new system that affirms urban Black male identity which is key to Black systematic success.

Connecting Cameron's systematic expression of justice to an individual level of justice/success, Jonathan expressed "Being a Black man means that you can go out in life and be whatever you want to be without having the constraint of 'being a Black man is supposed to do this, or a Black man should do that.' Being a Black man means be yourself to your fullest extent and be excellent and come together with your brothers and succeed." In this case, "be yourself, be excellent and come together with your brothers to succeed" is by the means and knowledge construction that is for the community and by the community. A knowledge construction that empowers Black men to be themselves with a framework that affirms what this authentic Black self looks like that is defined by 
the urban Black men themselves. The opposite of this is to continue to play into an oppressed, deficit lensed mindset based on structural inequality (which produces a sense of respectability politics).

The Black male deficit lensed mindset is an identity that tries to appeal to the consciousness of the White oppressive institution. For example, a student that feels that they cannot wear hood Black cultural style of dress attire, cannot say the word nigga or speak in a urban/Black dialect because the racist system deems this as "unprofessional" or "uncivilized." In other words, "not white." This is a deficit lens grounded in structural racism that deems Blackness as unhuman. MOB members Jonathan and Cameron Turner, in resisting anti Blackness, choose to build on a strength based Black lens in solidarity with their collective struggles (groundings with my brothers)- to impact empowerment and success. In other words, they don't want to be white. They want to be Black. Blackness, is the success.

This success, justice, is by means of resisting oppression and taking power into their own hands with their own knowledge construction that is grounded in the experiences of the oppressed Black masses. This is what it means to be a "N.I.G.G.A," opposed to a Nigger as Tupac Shakur constructed. A Nigger, based on how I define it in relation to student narrative, would be the process of students looking at their own collective oppression in a victim-oriented way; the deficit lens that I mentioned earlier. Again, this is a way that examines their Blackness through the lens of the opposer. A lens that has students running away from their collective Black identities and replacing them with "American dream" narratives of which they have to code switch their identity just to 
"fit in" white dominate spaces. Or to avoid being victimized by the police just as many students expressed throughout their narratives.

In contrast to this subservient Nigger identity that structural racist institutions try to push on Blacks. Tupac constructed N.I.G.G.A., meaning "Never Ignorant Getting Goals Accomplished." N.I.G.G.A. is as a call to action for the Black masses to be prideful in our collective struggles to challenge the oppressive institution. In connection, MOBISM is the political praxis for Black male MOB students to "Get Goals Accomplished," utilizing their collective racialized experiences as a source of empowerment to persist, resist and rebel against forces that get in the way of their success on an individual and systematic level via community leadership.

In connection to this, Kimane articulated "I do know now that there is a mission involved. And it's not just taking charge, but getting everyone else involved. I'm starting to understand that I want to be a leader. But not just an ordinary leader, but a servant leader where I can push my people to become excellent. At this point of my life, I don't really want to hold back, but I want to give back." Consistent with MOB members experiences navigating alienation during our MOB developmental stages: Consistent with MOB Member Narratives in response to the question "What Does MOB mean to you:" Consistent with data from MOB members expression within MOB activities that center on their blackness that further contextualize what MOB means to students: MOB members political praxis is grounded in putting in work for the community and resisting racism by being their authentic Black selves in navigating all spaces. 


\section{Chapter 5: Discussion, Implications, Conclusion \\ Discussion}

Existing literature on Black male success is guided by what success looks like in a way that places the Eurocentric institution on a pedestal. For example, with literature focusing on Black male achievement; graduating, academic success, or being retained by the Eurocentric institution is the primary focus. This often comes at the expense of invalidating Black identity given that the institution (which is shaped by a history of European colonialism), is a space that is not affirming to the lived experiences and values of urban Black males. For these reasons, the achievement gap model is problematic. Moreover, even with existing literature that does focus on CRP practices by including students lived experiences/culture into the education: The CRP is typically a means to an end to get students to succeed academically.

Data reflected in this MOBISM study builds on prior studies on cultural wealth and challenges the achievement gap literature by highlighting the racial, cultural, and community affirmation and politicization of Black males in the MOB study as most critical as praxis. Data from the MOBISM study reveals that when Black males are affirmed in their Blackness first, they have the confidence to accomplish whatever it is that they want to accomplish in life in a way that keeps their identities intact. From an academic lens, this is the claim that these students can be Black and hood, be critical/conscious and demonstrate high levels of academic achievement. In other words, they can have tatoo's on their face, have gold teeth in their mouth, speak in a urban Black dialect, even sag their pants and still get A's and Bs. The findings within this study, and how we are framing the findings reflect the above duality within MOB student outcomes 
that is grounded in MOB members development of Black consciousness as the foundation for their success. This duality reflects 1) MOB student success by means of achieving academically through means of resistance; and 2) MOB students resisting in the form of being anti-establishment and wanting nothing to do with the system overall, and instead they push to create their own system that is affirming to them.

\section{Academic Institutional Achievement Through Black Male Resistance}

The Black consciousness/resistance that I discuss is not contradictory to academic success. In fact, based on MOB student data, it facilitates academic success. MOB members come to this consciousness and develop attitudes of resistance through their active engagement with each other and the MOB program, and then come out on the other side as successful, even by the traditional academic terms. This is expressed when MOB student conveyed "I now recognize my identity as a Black man and the culture I stand from...I will assert myself in all spaces whether it be school, work or in life in general." Moreover, when MOB student conveyed "being a black man means when you get nocked down you gotta get back up... recognize our strength as Black men and get the knowledge and do college.” These narratives convey how students' Black consciousness and development of resistance attitudes facilitated forms of success within the institution for students.

In this case, Thug Life is a framework that gives Black males the confidence to be their authentic selves and resist educational barriers to impact their success. In illuminating some of the above positive academic outcomes, MOB has a 100 percent retention rate and has graduated 11 students from this study. Graduations occurred from spring 2017 for one student in 2017, four from Spring 2018, six from Spring 2019 
semester with one MOB member set to graduate college this Spring 2020. One of the Spring 2019 MOB graduates presented with me at the April, 2019 American Educational Research Association (AERA) conference in Canada focusing on this very work reflected in this dissertation. He graduated CSUEB with his degree in Engineering and has landed his first job out of undergrad in the field of engineering while continuing to focus on his artwork as a Hip Hop artist (of which he highlights his urban Black experiences throughout his art).

Our MOB graduates in general have landed positions as educators in the Oakland Unified School District (OUSD) and San Francisco Unified School District (SFUSD), currently are in graduate programs working on their master's degrees and continuing their work in the Black community. Furthermore, some MOB graduates currently serve as staff within the MOB organization. And one MOB member works with inner-city Black youth in the Hunters point district in San Francisco and has just developed his podcast that focusses on themes of Black liberation. His first podcast/show emphasized education on the second amendment and the importance for all Blacks to get gun licenses in preparation to bear arms against racist police and White supremacist. These success stories are important because they highlight how MOB has fostered Black male academic and professional success through forms of MOBISM. Which is a success groomed in resisting racism in their own way with their own knowledge construction, grounded in affirmation of their Black identities. Most critical, this political praxis to resist racism shaped another, perhaps more salient outcome in this study: Which is MOB students being anti -establishment and expressing forms of resistance against Eurocentric institutions overall. 


\section{Fuck the Academic Intuition as Black Male Resistance}

In connection to data, MOB members also expressed themes of "fuck the system...the system is designed to hurt Black people more." Furthermore, this student went on to say "when you introduce the truth to the system, it will be no more"-thus displaying aspirations to dismantle the system as it currently exists. In replacing this system, another MOB member said, "we need to work with Black youth to build our own community." The above anti-institutional Black male success outcomes are similar to the institutional success outcomes displayed in this study based on the following grounding: In both cases, MOB students focusing on their processes of racial alienation and resistance of this racial alienation, shaped both successful outcomes. Both outcomes represent what justice looks like to these Black males based on their racialized experiences. Yet, while still acknowledging and praising the academic achievement aspects found within MOB study; there is still a particular reason why it is critical to pay close attention, perhaps the most attention, to the anti-institutional/resistance frameworks expressed by MOB students in this study.

What if students get sick of playing the American Dream game and say "fuck school and the system"-as MOB members have already expressed in this study? What if Black male students and the larger oppressed Black masses want to take part in a praxis that dismantles the idea of "schooling" under the current Eurocentric colonial lens that schooling functions under? And instead, what if Black male students and the community want to fight "to build their own Black school and build their own community"-as MOB students have expressed in this study? Is this success? Achievement gap models would say no. But for MOB, yes this is an aspect of success. 


\section{Why Being Anti Institution is Critical}

I found it critical to utilize Tupac Shakur to uplift the racialization aspects found in MOB student data given that racial alienation and consciousness, resistance and antiinstitutional/establishment themes were the central concepts found in all student data. Also, literally all existing literature on Black male achievement point to a fact that Black males continue to struggle academically in their problem statement section. For me to focus on academic achievement solely in this study, would be me focusing on Black achievement at an individual level; when in reality students in this study point to issues of racial discrimination as the thing that keeps Blacks by the masses from achieving in life in general. To this point, will we ever get to a point where Black men can achieve academically by the masses, in education institutions as they currently exist under European norms and values?

When MOB student stated, "there is no point in trying to work within the system because it was designed to do exactly what it is doing:" Does this student not have a point? There is constant literature, decade after decade, on Black male achievement problems which means this is a problem on a systematic level. Meaning that there are factors outside of the institution such as structural and systematic dehumanization that MOB members pointed to as a recognition that these larger issues also impact the educational space. As such, a need for praxis to address the larger problem of racism, and not just themes of achievement within the academic institution.

Based on data that centered on MOB student encounters with structural racism that Blacks face at the community/structural level, we must examine MOB members following expressions found in the study: "Fuck the system;" "lets build our own 
community and schools;" "teach Black youth;" "make sure every Black person is supported no matter where they are at;" "the system is a problem;" "all we gotta do is keep mobbin and do our own thang." These Black male expressions are produced by, and in response to, the existing literature that continue to highlight Black male deficits. MOB students expressed that they "are tired of constantly being viewed as victims" in society and a need to "take matters in our own hands" to liberate themselves. This is MOB members recognition that the institution does not want to see Black male academic achievement by the masses. Furthermore, it is a recognition that "they don't give a fuck about us" (Shakur, 1997). To pay closer attention to this expression is to expand the work beyond a pedagogical focus of academic success. And instead, to commit to a lifestyle of resistance grounded in how urban Black youth express praxis.

\section{MOBISM Key Construction}

The below key construction helps us understand MOB members path to MOBISM along their experiences in the MOB program featured in this study. It is important to understand that this is a path in which students have critically reflected on their experiences with racial alienation. Through this reflection, they developed mechanisms to challenge these forces both individually and collectively. Because achievement gap and CRP models often center Black male success within the institution, it produces an unconscious respect for those institutional politics. In this case, the achievement gap model does not illuminate the experiences of urban Black males because urban Black males' processes of alienation at the structural level prompts them to resist institutional discrimination. The below MOBISM key is significant in 
understanding Black males need for developing mechanisms to resist racism on a collective level-as a means to Black male success.

\section{Recognition of Inequality/Individualized Racism and Dehumanization: The} experiences of discrimination that Black male MOB members experience at the individual level. These racialized experiences serve as focal point for the historical and contemporary lived experiences of Blacks male students in the MOB program. MOB member experiences of discrimination at the individual level are affirmed by a community of peers that share the same struggle on a structural level : $\underline{\text { Recognition of a }}$ Community of Oppressed Students recognize that they are part of a community of peers that share the same struggle. Being part of a community that navigates racial discrimination together establishes a sense of belonging for Black males along this community struggle. Once students are affirmed in their collective struggle dealing with racism as community, this shapes: Recognition of Communal Struggle/Solidarity: This is the stage where Black male MOB members build a sense pride in their shared struggle, thus building solidarity as a community to resist racism. This pride and solidarity in communal struggle impacts: Political Praxis Rooted in Racial Alienation-MOBISM: Based on MOB members established solidarity in communal struggle; this is the stage of which MOB members recognize and live by a commitment to justice by resisting racism individually and collectively in whatever way this means to students.

Although the above MOBISM key is broken down in a linear format, it is key to remember that findings from study express this path to MOBISM for students as a continuum. However, for some students, especially for certain aspects within the four stages; their path can be linear. Based on MOB members path to MOBISM reflected in 
the findings of this study, there are larger implications for Black males, educators, and community members overall. These implications are closely tied to the political process rooted in racial alienation (MOBISM) within this study.

\section{Implications for Best Practice}

MOB members in this study indicated that when they were confronted with discrimination or put in positions that compromised their "authentic Black identity" in their education experiences; it was followed by students developing a political praxis to resist that discrimination in some way. For example, MOB member expressed that once he was empowered in his identity as a Black man in alignment with the culture that he stands from, he was not only compelled to resist by asserting himself in all spaces in life; but resist racism by empowering Black youth of the larger community and pushing for Blacks to be supported in all spaces (school and society) that they are in. Moreover, as mentioned, another MOB member expressed that there was no point in believing in or working to fix the system because the system is designed to work exactly how it is working. Meaning that there is no point in navigating the institution in ways that the system wants the oppressed to navigate it. Instead, this student was interested in dismantling the system by "introducing the truth to system," as a weapon. This MOB member's truth was an education grounded in his collective racialized experiences for a Black system, that works for Black people, to impact Black success.

This implies 1) respectability politics is no good as a process to impact urban Black male success. And 2) to impact urban Black male success: The only respectability politics that matter are the politics of the urban Black masses regarding how Black males choose 
to resist and build. And 3) there is a need for more spaces, programs, leaders, educators, and educational politics that are dedicated to a praxis that focusses on the above phenomenon. Which is a framework that is Strictly For My N.I.G.G.A.Z. Meaning to strictly privilege the knowledge construction of urban Black males in solidarity with their communal struggle.

If the lives of first-generation college Black males have any value to 4-year college institutions, this study implies that stake holders need to hire real models, not role models, in leadership positions to support the growth of Black male students. A real model is an authentic Black leader. Authentic Black leadership is a leadership approach that holds true to the authenticity that is defined by and grounded in solidarity with the urban Black masses. If institutions are serious about engaging urban Black male youth then they would hire leaders that can resonate, and be in solidarity with, the population of students that they are serving. Opposed to hiring folks that fit in with the "office culture" of the institution, which in most cases is a Eurocentric dominant culture that students cannot resonate with in the first place. Most critical implication: If institutions as they exist right now, cannot honor the identity and knowledge construction of the urban Black masses-which I believe they will not. Then the implication from this study is for a collective sense of MOBISM and Thug Life. This is aligned with revolutionary praxis to build our own educational institutions to affirm us and do by all means to protect them. 


\section{Conclusion: Future Directions}

In upholding the theme "Strictly For My Niggaz," the future direction of MOB work is just that. It is a complete focus of the work in the urban Black community. With many MOB members graduating from college, I decided to pick up where they left off in focusing our work primarily in community by establishing more K-12 partnerships. When we started MOB, West Oakland Middle School was our only school site for outreach and community work of which undergraduate Black men mentored K-12 Black youth. Now, we have McClymonds High School and Castlemont High School as school sites of which MOB partners more with community members within the K-12 school, and the surrounding community to impact youth. The community work is the focal point of the program.

Regarding community, our MOB work now centers on an approach that focuses on community mapping. Community mapping involves a politicization process of which urban Black K-12 youth in the MOB program construct what success looks like to them based on their own strength based ethnographic research within their hoods/communities; grounded in their racialized meaning making systems (Akom et al, 2016). This includes our Oakland youth constructing MOB codes (modeled after the Code of Thug Life) of which students focus on creating their own set of codes defined by what students think the Black community must do in order to resist alienation and thrive in this world. These community mapping projects focus on what students see and feel in their communities as they walk around their communities and map out what the strengths are in the community (Akom et al, 2016). 
An example of community strength may be the following: If a student sees a group of Black men and women hanging out in the hood and the student maps this as "Black people together," that is interpreted through our lens- as a good thing. Then we know that this student is conveying that Black people being together in some capacity (community) is something that may be key to their success. This is just one small example that shall be built on in future research to come. This approach can challenge future work on CRP to be more community responsive to educate youth according to how the youth see themselves and what they deem important to them.

. If educators truly privilege the knowledge construction of urban Black students within these community mapping projects, this approach may also prompt Black community educators and Black scholars to leave their White institutional positions and commit their capital to be in solidarity with urban Black youth in building our own schools and communities. Perhaps some of the "Black people together" expressed by this student example, can play a role in protecting the communities and schools that we build.

In this regard, this is a call for educators to pay attention and listen to what youth are saying, -and to design and implement educational experiences accordingly. In connection, the future direction of MOB can inform future contributions to research that privileges the knowledge construction of Black youth through research to impact practice. Grounded in this knowledge construction, "groundings with my brothers;" MOB's future considerations will be focused on being real N.I.G.G.A.S in our collective commitment to being "Never Ignorant Getting Goals Accomplished." 


\section{References}

Akom, A. (2006). The Racial Dimensions of Social Capital: Toward a New Understanding of Youth Empowerment and Community organizing in America's Urban Core

Akom, A. (2009). Critical Hip Hop Pedagogy as a Form of Liberatory Praxis. Equity \& Excellence in Education, 42(1), 52-66. doi: 10.1080/10665680802612519

Akom, A. (2011). Black emancipatory action research: Integrating a theory of structural racialization into ethnographic and participatory action research methods. Ethnography and Education, 6(1), 113-131.

Akom, A. (2016). Youth Participatory Action Research (YPAR) 2.0: How Technological Innovation and Digital Organizing Sparked a Food Revolution in East Oakland.

Brooms, D. (2018). Exploring Black Male Initiative Programs: Potential and possibilities for supporting Black male success in college. The Journal of Negro Education, 87(7), 5972.

Brown, E., Bargainer, G. (2018). Race and Crime: Geographies of Injustice. Oakland, California: University of California Press.

Chavous, T. M., Rivas-Drake, D., Smalls, C., Griffin, T., \& Cogburn, C. (2008). Gender matters, too: The Influences of school racial discrimination and racial identity on academic engagement outcomes among African American adolescents. Developmental Psychology, 44(3), 637-654.

Cooks, J. A. (2004). Writing for something: Essays, raps and writing preferences. The English Journal, 94(4), 72-76. 
Duncan-Andrade, J. M. R. (2002). Toward a critical classroom discourse: Promoting academic literacy through engaging hip hop culture with urban youth. English Journal, 91(6), 88-94.

Duncan-Andrade, J. M. R., \& Morelle, E (2008). The art of critical pedagogy: possibilities for moving from theory to practice in urban schools. New York: Peter Lang.

Dyson, M. (2006). Holler If You Hear Me (2006). Basic Books.

Emdin, C. (2011). Moving beyond the boat without a paddle: reality pedagogy, black youth, and urban science education. The Journal of the Negro Education, 80(3), 284-295.

Fryer, R. G., Heaton, P. S., Levitt, S. D., \& Murphy, K. M. (2006). Measuring crack cocaine and its impact. Economic Inquiry, 51(3), 1651-1681.

Harper, S. (2006). Black male students at public flagship universities in the U.S.: Status, trends, and implications for policy and best practice. Washington, DC: Joint Center for Political and Economic Studies.

Harper, S. (2012). Black male student success in higher education: A Report for the national black male college achievement study. Philadelphia: University of Pennsylvania, Center for the Study of Race and Equity in Education.

Harper, S. R., Wood, J. L. (2016). Advancing Black male students success from preschool through Ph.D. Sterling, VA: Stylus Publishing.

Harris, F., \& Wood, J. L. (2013). Student success for men of color in community colleges: A review of published literature and research, 1998-2012. Journal of Diversity in Higher Education, 6(3), 174-185. doi: 10.1037/a0034224

Hope, E. C., Skoog, A. B., Jagers, R. J. (2014). 'It'll never be the White kids, it'll always be us": Black high school students' evolving critical analysis of racial discrimination and 
inequity in schools. Journal of Research and Adolescent Research, 30(1), 83-112. https://doi.org/10.1177/0743558414550688.

Hotchkins, B. K. \& Dancy II, T. E. (2016). Rethinking excellence: Black male success and academic values in higher education. Spectrum: A Journal on Black Men, 4(1), 7398. doi: 10.2979/spectrum.4.1.05.

Howard, T. C. (2003). Culturally relevant pedagogy: Ingredients for critical teacher reflection. Theory into Practice, 42(3), 195-202.

Na'llah, N. (2013). Dirt on my record: Rethinking disciplinary practices in an All-Black, allmale alternative class. Harvard Educational Review, 83(3), 489-512.

Newton, H. P. (1980). War Against the Panthers: A Study of Repression in America. [Doctoral Dissertation UC Santa Cruz]. ProQuest Dissertations Publishing.

Noguera, P. A. (2008). The trouble with Black boys: And other reflections on race, equity, and the future of public education. Jossey-Bass.

Rodney, W. (1969). The groundings with my brothers. London: Bogle-L'Ouverture Publications.

Shakur, M. (2019, December 2). Mutulu Shakur Jail interview Pt1 [Video File]. Retrieved from https://www.youtube.com/watch?v=4dZLZq0OIoc

Shakur, T. (1991). Words of Wisdom [Song]. On 2Pacalypse Now [Album]. Interscope Records.

Shakur, T. (1993). Strictly 4 My N.I.G.G.A.Z [Song]. On Strictly 4 My N.I.G.G.A.Z. [Album]. Interscope Records.

Shakur, T. (1994). Cradle to the Grave [Song]. Thug Life Volume 1 [Album]. Out Da Gutta Records. 
Shakur, T. (1998). Changes [Song]. Tupac's Greatest Hits [Album]. Interscope Records.

Shakur, T. (2001). When Thugs Cry [Song]. Until The End Of Time [Album]. Amaru; Death Row; Interscope Records.

Shakur, T., \& Shakur, M. (1992): Code of Thug Life. Newafrikan77.workpress.com. Retrieved from: https://newafrikan77.wordpress.com/2018/06/13/code-of-thug-life1992-dr-mutulu-shakur-tupac-shakur-mopreme/.

Shakur, T. \& Outlawz. (1999). Letter to President. Still I Rise [Album]. Interscope Records.

Solorzano, D. G., \& Bernal, D. D. (2001). Examining Transformational Resistance through a Critical Race and Latcrit Theory Framework. Urban Education, 36(3), 308-342. doi: $10.1177 / 004208590136302$

Tierney, W. G. (1999). Models of minority college-going and retention: Cultural integrity versus cultural suicide. The Journal of the Negro Education, 68(1), 80-91.

Tuhiwai-Smith, L. (1999). Decolonizing Methodologies: Research and Indigenous Peoples. London: Zed Books.

Yosso, T. J. (2006). Whose culture has capital: A critical race theory discussion of community cultural wealth. Journal of Race and Ethnicity in Education, 8, 69-91. 